\title{
Recent Progress on the Fabrication of Ultrafine Polyamide-6 Based Nanofibers Via Electro- spinning: A Topical Review
}

\author{
R. Nirmala ${ }^{1,3, *}$, R. Navamathavan ${ }^{2}$, Soo-Jin Park ${ }^{3}$, Hak Yong Kim ${ }^{1}$
}

(Received 12 November 2013; accepted 18 Feburay 2013; published online 20 March 2014)

\begin{abstract}
Electrospinning is a highly versatile technique to prepare continuous fibers with diameters of the order of nanometers. The remarkable high aspect ratio and high porosity bring electrospun nanofibers highly attractive to various nanotechnological applications such as filtration membranes, protective clothing, drug delivery, tissue-engineering, biosensors, catalysis, fuel cells and so on. In this review, we collectively summarized the recent progress in developments of the electrospun ultrafine polyamide- 6 based nanofibers preparation, characterization and their applications. Information of this polyamide- 6 and composites together with their processing conditions for electrospinning of ultrafine nanofibers has been summarized in this review. The recent developments made during last few years on these materials are addressed in this review. We are anticipating that this review certainly drive the researchers for developing more intensive investigation for exploring in many technological areas.
\end{abstract}

Keywords: Polymers; Electrospinning; Ultrafine nanofibers; Experimental parameters

Citation: R. Nirmala, R. Navamathavan, Soo-Jin Park and Hak Yong Kim, "Recent Progress on the Fabrication of Ultrafine Polyamide-6 Based Nanofibers Via Electrospinning: A Topical Review", Nano-Micro Lett. 6(2), 89-107 (2014). http://dx.doi.org/10.5101/nml.v6i2.p89-107

\section{Introduction}

One-dimensional nanostructures that include fibers, wires, rods, belts and tubes have attracted rapidly growing interest due to their fascinating properties and unique applications [1-5]. Electrospinning is currently used as the unique technique that allows the fabrication of continuous fibers with diameters down to a few nanometers. It is the most famous technique for the production of high aspect ratio nanofibers and microfibers. The equipment required for electrospinning is simple, readily available, and inexpensive. Nanofibers are traditionally defined as nanostructures with a diameter below $1000 \mathrm{~nm}$ and a length-to-width ratio typically greater than 50. During electrospinning process, a continuous strand of a polymer liquid was drawn through a spinneret by a high electrostatic force to deposit randomly on a grounded collector as a mat. These electrospun fibers possess small inter-fibrous pore size and high surface area to volume ratio than that of the bulk materials [6-8]. The electrospinning process is robust, and results are reproducible, although the process controls to produce samples with high uniformity at a specified diameter are just emerging. The performance and applications of many nanomaterials strongly rely on their morphological and structural properties. Processing nanomaterials in to appropriate structures often improves their performances and can even extend their range of applications $[9,10]$. In this connection, electrospun nanofibers, the focus of the present review, are recently emerging as important building blocks for variety of technological applications which includes fil-

\footnotetext{
${ }^{1}$ Department of Organic Materials and Fiber Engineering, Chonbuk National University, Jeonju, 561-756, South Korea

${ }^{2}$ School of Advanced Materials Engineering, Chonbuk National University, Jeonju 561-756, South Korea

${ }^{3}$ Department of Chemistry, Inha University, Nam-gu, Incheon 402-751, South Korea

*Corresponding author. E-mail: rnn12@yahoo.com (R. Nirmala); sjpark@inha.ac.kr (Soo-Jin Park); khy@jbnu.ac.kr (Hak Yong Kim)
} 
tration membranes [11-13], solid phase extraction [14], protective textile [15-17], sensors and biosensors [18-22], catalysis [23, 24], photovoltaic cells [25], wound dressing [26-29], scaffolds in tissue engineering [30-40], drug delivery [41-44], fuel cells [45-48], dye-sensitized solar cells $[49,50]$, super capacitors [51] and some other applications [52-55].

At the present scenario it attained a new dimension for the production of high aspect ratio fibers in subnano scale in the range of 5 to $15 \mathrm{~nm}$ in diameters. Recently, a variety of materials including polymers, ceramics, semiconductors and metals have been electrospun in to high aspect ratio ultrafine nanofibers structure [56-63]. Because of these interesting morphological features, this cutting-edge technology paves an intensive research in nano-scale. The internal structure of nanofibers can accommodate molecules, chemical reactions, separated phases, and even hold large particles. Experimental factors that affect the final diameter are described [64-67]. Even thinner segments of fibers are occasionally observed, and there is a strong possibility that even single polymer molecules can be held in an extended form by the forces associated with the electrospinning process. Single polymer molecules, extended by the excess electrical charge they carry, may already be present in the electrostatic spray methods used for the injection of molecules into a mass spectrometer.

Recently, growing attempts were focused to control the diameter of electrospun nanofibers to achieve desired functions [68-70]. Ding et al. [71] observed this kind of fishnet-like morphology in electrospun nylon-6 and poly (acrylic acid) (PAA) nanofibers, and they reported that the formation of such kind of morphology was due to applied voltage, relative humidity, kinds of solvents, solution concentration and distance between the capillary tip and the collector in the electrospinning chamber. Nylon-6, polyurethane and poly (vinyl alcohol) (PVA) polymeric nanofiber mats containing spidernet morphology have been synthesized by the addition of metallic salt [8]. Parajuli et al. reported that a spider netlike arrangement of fibers with an average diameter of $18 \mathrm{~nm}$ by the polymerization of PAA with nylon [72].

More than 100 kinds of polymers have been used to obtain their nanofibers by using electrospinning technology during the past two decades. Electrospinning process of different kinds of polymers and their composite was discussed based on the variety of aspects which include the experimental parameters, reduce the fiber diameter, blending other composites, alignment, orientation and so on [73-75]. Several polymers are combined with other composite materials to obtain composite nanofibers. The resultant composite nanofibers leads to substantial improvements in terms of structural, mechanical, thermal, electrical, and biological properties compared to that of pristine nanofibers. Many unique qualities that include intrinsically high specific surface area, extremely small diameter and high porosity as a result of the electrospun fibers have drawn interests in many research groups around the world [76,77]. Variety of polymer nanofibers has been recently produced in terms of research interest because of their potential applications in diverse fields [78-81]. Recently, Wang et al. reported the comprehensive review of the stateof-the-art research activities related to electrospinning of polymer nanofibers which include their fabrication, novel properties studies and potential applications [82].

The growing interest in the utilization of these nanostructures primarily stems from their unique physical, mechanical and electrical properties associated with their very high surface area. These properties make nanofibers suitable for the creation of numerous technologically advanced products within many fields of application. With development activities related to nanofiber technology intensifying rapidly, one can reasonably project that these nanostructures will achieve widespread commercialization within the next 5 to 10 years. Another important reason for performing this study is to supply a review of nanofiber manufacturing methods, to identify current technical issues, and to illustrate the latest technological developments and how they will useful for further research directions.

The diameters of polymer fibers are around nanometers size, from few tens nanometers to micrometers as example of polymer nanofibers, even though, it is still difficult to electro spin polymer into uniform nanofibers with diameter as small as few hundred nanometers up to now. The high aspect ratio nanofibers are defined as the formation of ultrafine nanostructure in between the main nanofibers. In other words, the ultrafine nanofibers can have the reduced diameter of one order than that of the main nanofibers. Typically, the ultrafine nanofibers consisted of regularly distributed very fine nanofibers with diameters of about 7 to 30 $\mathrm{nm}$ whereas the main nanofibers are in the ranges of $100-300 \mathrm{~nm}$ in size. Consequently, the peculiar structural morphology of the ultrafine nanofibers made a very deep interest among many research groups since these kind of characteristics can be utilized for many scientific and industrial purposes. Some of the specific applications of these ultrafine nanofibers are of filtrations, sensors, targeted drug delivery systems, and so on.

Electrospun nanofibers are extensively studied and their potential applications are largely demonstrated. Today, electrospinning equipment and technological solutions, and electrospun nanofiber materials are rapidly moving to commercialization. Multifunctional capability, flexible design, rugged, light weight construction and self-powered operation are desired attributes for electronics that directly interface with the human body or with advanced robotic systems. For these applications, piezoelectric materials, in forms that offer the 
ability to bend and stretch, are attractive for pressure/force sensors and mechanical energy harvesters. A large area, flexible piezoelectric material that consists of sheets of electrospun nanofibers of the polymer poly(vinylidenefluoride-co-trifluoroethylene] have been reported [83]. Cho et al. [84] have collectively reported about the recent studies in electronic and photonic applications of electrospun organic nanofibers which include organic light-emitting diodes, organic photovoltaics, organics field-effect transistors, lasers and waveguides. Further, there have been number of review articles published which provides an insight into the most prominent aspects of preparation, characterization of electrospun nanofibers and their applications [1,18,85-89]. Persano et al. [90] have briefly reviewed about the industrial up scaling of electrospinning and applications of polymer nanofibers. And in another article, Luo et al. [91] have elaborately reported about the combination interdisciplinary knowledge from the academia and industry to facilitate technological convergence and offers insight for up scaling electrospinning and nanofibers production. They have also discussed about the advances in electrospinning within a framework of large-scale fiber production as well as alternative nanofibers forming methods, providing a comprehensive comparison of conventional and contemporary fiber forming technologies.

In this review, we specifically summarize most recent progress in developments of the ultrafine electrospun nanofibers based on polyamide- 6 and their composites. Thus, herein we address the current developments, including preparation, synthesis and characterization of these nanofibers via electrospinnng process. At the same time, we provide some potential applications associated with polyamide- 6 based electrospun nanofibers.

\section{Synthesis of ultrafine nanofibers}

In electrospinning, a strong electrical field is applied to a droplet formed by a polymer solution or polymer melt at the tip of a die acting as one of the electrodes.
Figure 1 shows the schematic diagram of electrospinning set up and typical images of nanofibers morphology. The charging of the fluid leads to a conical deformation of the droplet, the well-known Taylor cone [92-94] and eventually to the ejection of a jet from the tip of the cone. Taylor found that the critical field required for such deformation is strongly controlled by the surface tension. The electric dispersion of liquids based on this phenomenon is widely used today, for instance in ink jet printing, for crop spraying, to prepare aerosols from liquids, and to produce propellants for rockets. The tip-to-collector distance was kept as $15 \mathrm{~cm}$. Polymer solution was fed to the $5 \mathrm{ml}$ syringe with plastic micro-tip with a diameter of $0.3 \mathrm{~mm}$ and $10 \mathrm{~mm}$ length. During the electrospinning process, the drum was rotated at a constant speed by a DC motor to collect the developing nanofibers. When a polymer solution is forced through a spinneret, the process aligns the chain in the direction of the extrusion with a similar alignment of the crystallites if the solid polymer is partially crystalline [95]. The additional orientation that is typically imposed after the spinning causes additional alignment of the crystallites, and the stretching and alignment of the amorphous chains separating the crystallites. In the polymer electrospinning process, several experimental parameters such as solvents, concentration of the polymer solution, applied voltage, surface energy, electrical conductivity, flow rate and humidity play an important role in confining the morphology of the resultant nanofibers [64,96-98].

\section{Choice of system and parameters}

\section{Effect of applied voltage}

In the electrospinning process, sub-nano diameter polymer fibers can be produced when a high potential difference is applied to a polymer drop suspended at the tip of a capillary. The electrospinning process is affected by a wide range of parameters, because of which controlling the properties of the fibers is difficult.
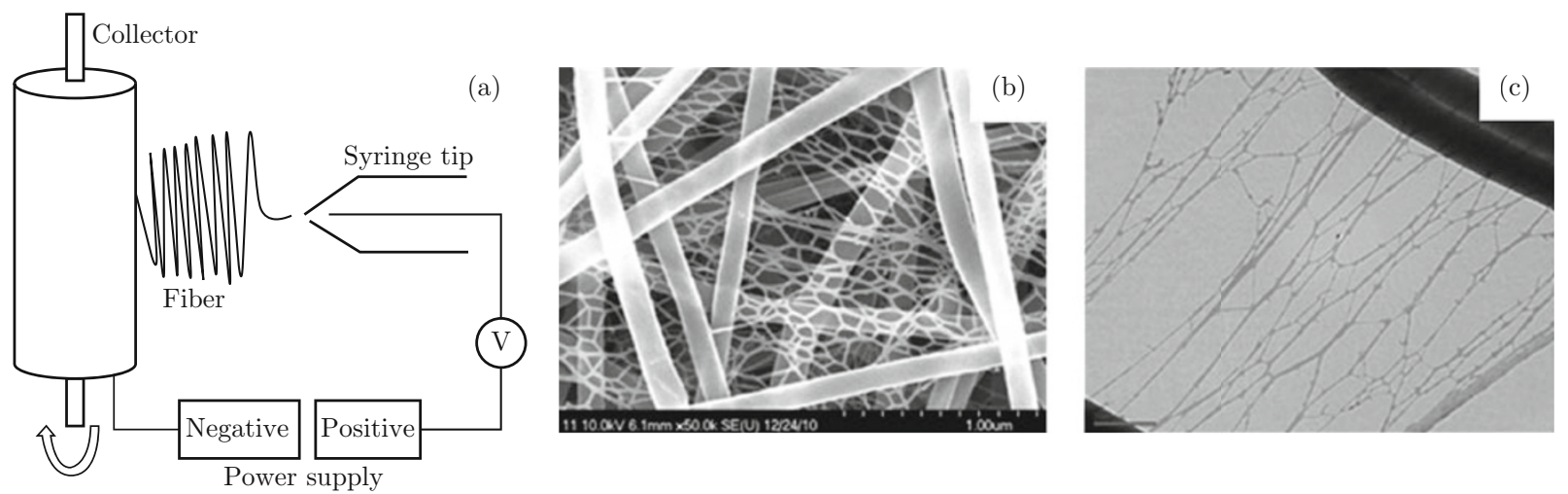

Fig. 1 Nanofiberous structures obtained by Electrospinning process. (a) Schematic diagram of electrospinning set up, (b) FE-SEM and (c) HR-TEM image of high aspect ratio nanofibers. (Reprinted from [65] with the permission from Elsevier). 
Typically the polymer solution is taken in a capillary and a high voltage power source is connected to generate an electric field between the tip of the capillary and a grounded collector. The drop is held at the tip of the capillary because of surface tension. As the voltage is increased, the viscoelastic forces are overcome by electric forces because of which the droplet gets distorted.

The formation of ultrafine polyamide- 6 nanofibers were investigated by Nirmala et al. [65] by varying the applied voltages. They observed the web-like nanofibers morphology of the electrospun polyamide- 6 nanofibers at a certain applied voltage. As the applied voltage was increased to $22 \mathrm{kV}$, more amount of surface area to volume ratio nanofibers was well formed. The formation of high aspect ratio nanofibers was strongly bound in between the main fibers. High voltage is able to generate more charges to the solution or droplet surface located at the tip of the needle as well as larger electrostatic forces, both of which stretch the jets fully for the favorable formation of the ultrafine nanofibers and completely split nano-nets. At the same time, too high applied voltage, the formation of high aspect ratio nanofibers was reduced and somewhat loosely bound to the main fibers. Therefore, the applied voltage plays an important role in forming the uniform fiber mats. Very clear arrangements of ultrafine fibers strongly bound with the main fibers were observed. The diameter of the polyamide- 6 nanofibers were observed to be in the range of 75 to $110 \mathrm{~nm}$, whereas the high aspect ratio structures consisted of regularly distributed very fine nanofibers with diameters of about 9 to $28 \mathrm{~nm}$ (Fig. 2).

To further support their claim, the presence of electrically induced double layer in the micro-tip solution was directly evidenced by the TEM observation which further split-up in the formation ultrafine fibers in between the main fibers (Fig. 3). Generally, the polymers bearing reactive functional groups may yield reactions of chemical exchange when they are mixed with solvent, leading to the formation of block, segmented, or random copolymers [99]. Formic acid, a polar protic solvent with high dielectric constant and low polarity is capable of attacking the lactam to produce a series of short chain oligomers, $-\mathrm{CONH}_{2}-^{+}$ and formate ions $\left(\mathrm{HCOO}^{-}\right)$[96]. The primary step involves the hydrolysis of caprolactam to the amino acid $\left[\mathrm{H}_{2} \mathrm{~N}\left(\mathrm{CH}_{2}\right)_{5} \mathrm{COOH}\right]$. The further reaction involves either a direct ring-opening attack of amino acid on caprolactam or a process in which the amino acid zwitterions, $\mathrm{H}_{3} \mathrm{~N}^{+}\left(\mathrm{CH}_{2}\right)_{5} \mathrm{COO}^{-}$, undergoes a ring-opening attack on the cyclic monomer [101]. Therefore, the poly-electrolytic (for example, anionic, cationic and zwitterionic products) polyamide-6 in formic acid was attributed to the partial ionization of the amide groups along the polymer chains. Furthermore, the electrospinning of polymer from highly polar solvents leads to smaller fiber diameters. Consequently, the applied electrostatic field can facilitate an increased mass throughput of the solution from the spinneret. The results indicated that the polyamide- 6 showed an optimal balance of interaction with the solvent and electrical conductivity of the polymer solution, ultimately resulting in high aspect ratio nanofibers.

Further, to better understand the formation of this peculiar morphology in between the main fibers with a probable mechanism (Fig. 4). Too low applied voltage (less than $12 \mathrm{kV}$ ) could not sufficiently ionize the
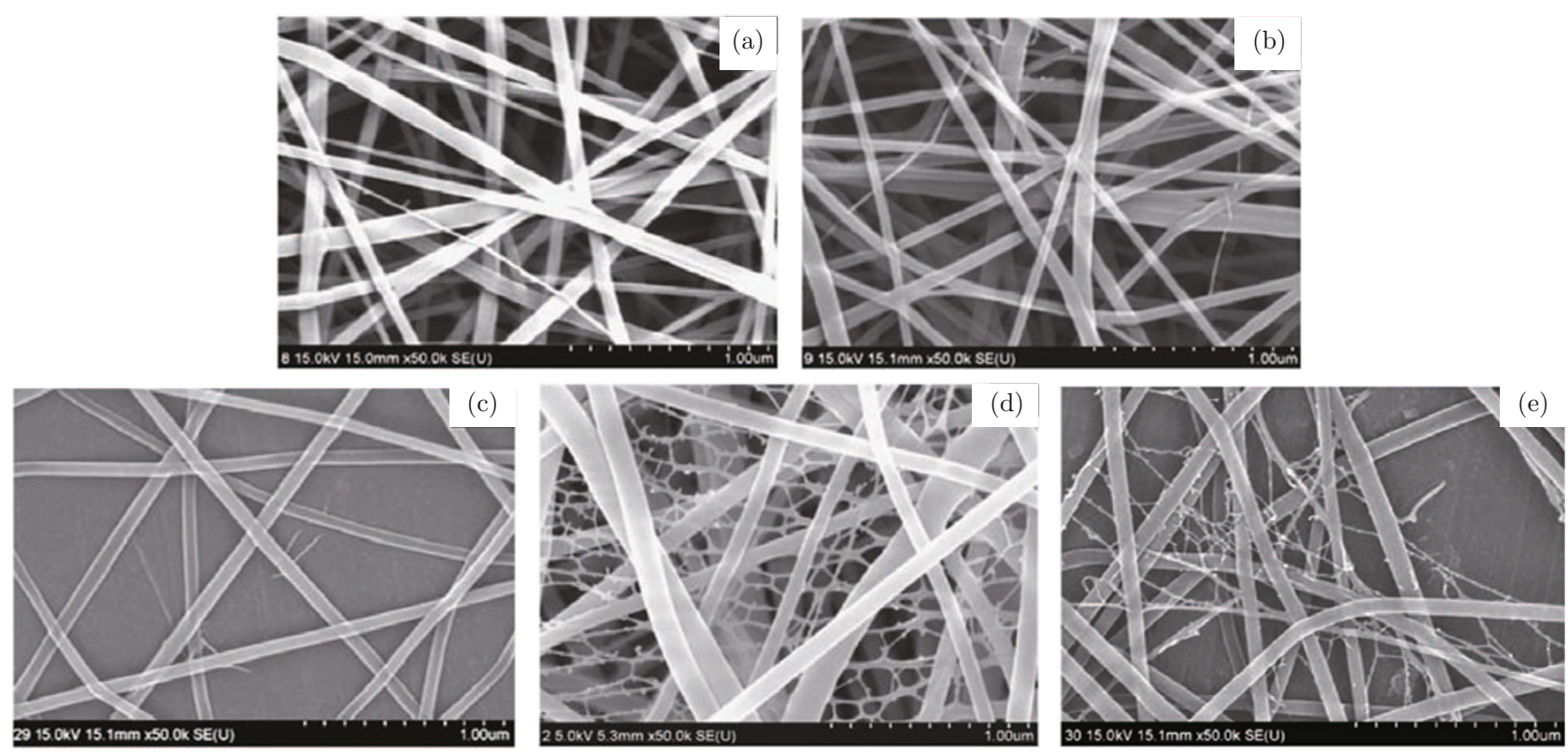

Fig. 2 FE-SEM images of electrospun polyamide-6 produced with different applied voltages of (a) 15; (b) 17; (c) 19; (d) 22 and (e) $25 \mathrm{kV}$. (Reprinted from [65] with the permission from Elsevier). 

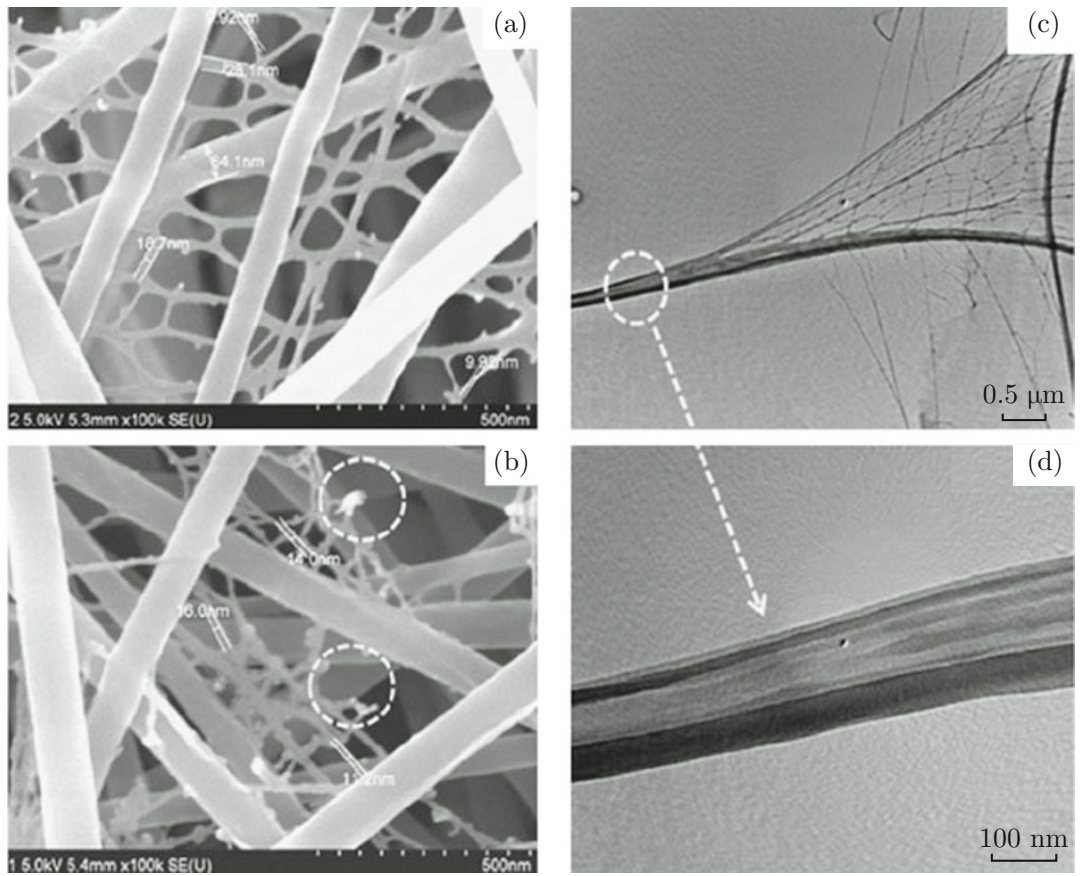

Fig. 3 High-resolution FE-SEM of electrospun polyamide-6 nanofibers ((a),(b)) and the HR-TEM images showing (c) the high aspect ratio nanofibers formation during electrospinning process and (d) the magnified region of the double layer. (Reprinted from [65] with the permission from Elsevier).

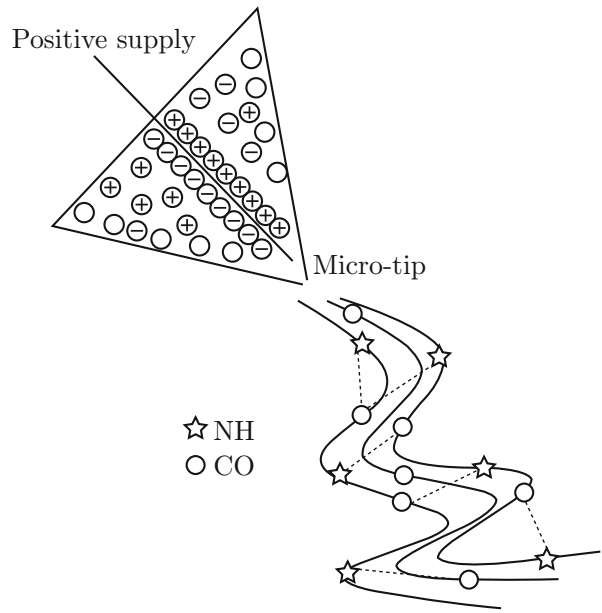

Fig. 4 Schematic diagram showing the mechanism of electrical double layer for the high aspect ratio nanofibers formation in polyamide-6 (Reprinted from [65] with the permission from Elsevier).

molecules, which was attributed to the generation of bulk and elongated beads within the fiber mat. This is because only a small proportion of the polymer molecules (for example, $\mathrm{CO}$ and $\mathrm{NH}$ groups' reaction with free ions) can interact in the low applied voltage. In other words, the solution was not sufficiently ionized. Further increase in applied voltage $(19 \mathrm{kV})$ can just to initiate the splitting up of sub-nanofibers in between the main fibers. At an applied voltage of $22 \mathrm{kV}$, the solution can be completely ionized. Although the solution retains its overall electrical neutrality, the distributed charges inside the solution were subjected to a spatially dependent electric field that may give rise to electrical stresses [102]. The critical applied voltage causes the formation of an electric double layer next to the solid surface due to the poly-electrolytic behavior of polyamide-6. Furthermore, the induced surface charges can attract the counter ions from the solution. At this stage, the ions in the double layer migrate and drive further ionized solution. Thus, the electric double layer become thinner and then the ionized solution can be aligned as high aspect ratio structures in between the main fibers by relaxing the electrical stress. The ions in the electric double layer interact with the applied voltage, resulting in a nonlinear electro-osmotic flow. This proposed mechanism is directly evidenced by the TEM results in which the formation of double layer and then split-up into ultrafine fibers (Fig. 3). At an applied voltage greater than $22 \mathrm{kV}$, the solution can be ionized more strongly and became electrically unstable state. At this stage, these highly ionized particles could not retain in between the main fibers to form the high aspect ratio nanofibers. Rather, it detached and simply escaped from the main fibers due to very high ionized state. When we further increased the applied voltage, we observed sparks due to uncontrollable generation of ionized particles from the solutions.

\section{Effect of inorganic salt}

Recently, Barakat et al. [8] reported that the use of inorganic salt and polymers to properly study the influence of salt nature, polymer solution and stirring time 
on the internal morphology of the electrospun nanofiber mats. They have elaborately studied the effect of inorganic salts (sodium chloride and calcium chloride) addition on nylon 6, poly. (vinyl alcohol) (PVA) and polyurethane. The salts of these metals might be utilized to improve the general characteristics of the electrospun polymer nanofiber mats by modification of the internal structure. It was observed that the addition of the inorganic salts resulted in the formation of multilayers spider-network morphology in nylon 6 and PVA within the electrospun nanofibers mats. The metallic acid (hydrogen hexacholorplatinate solution) led to form trivial spider-nets within both of nylon 6 and PVA nanofibers. On the other hand, for polyurethane, few spider-nets were formed after salt addition due to the low polarity of the utilized solvents (Tetrahydrofuran and N,N-dimethylformamide).

The nature of sol-gel/polymer solution which has been utilized by many researchers to produce metal oxides nanofibers (Fig. 5(A)). The produced polymeric nanofibers embed the ionically balanced sol-gel particles which were formed due to hydrolyzing and polycondensation of the utilized precursor, no spider-net had been observed within the electrospun nanofiber mats of such solutions (Fig. 5(B)). Therefore, calcination of the electrospun nanofiber mat leads to complete elimination of the polymer and decomposition of the condensate precursor to metal oxide in good nanofibrous shape as so many researchers have concluded [103]. However, it is expected that the utilized salt/polymer solution in the present study might have the semblance (Fig. 5(C)). With long mixing time, the ions randomly spread in the solution and might attach with the polymer chains. Therefore, electrospinning of such solutions can be interpreted (Fig. 5(D)). As aforementioned, the instantly formed nanofibers at the tip end would contain solvent, and it is expected that these nanofibers are not ionically balanced. Consequently, one can say that the different charges tinny electric poles which are generated in the nanofibers led to synthesize joints between each two different charge poles (Fig. 5(D)). The electric poles can also present in the recently formed joints which results in creating other connections between these new joints. The low- and high-magnified FESEM images of the resultant inorganic salt incorporated nylon-6 nanofibers are shown in Fig. 5(b) and 5(c), respectively. The synthesized joints finally shape the observed spider-network within the electrospun nanofiber mats (Fig. 6). This hypothesis can be supported by TEM results.
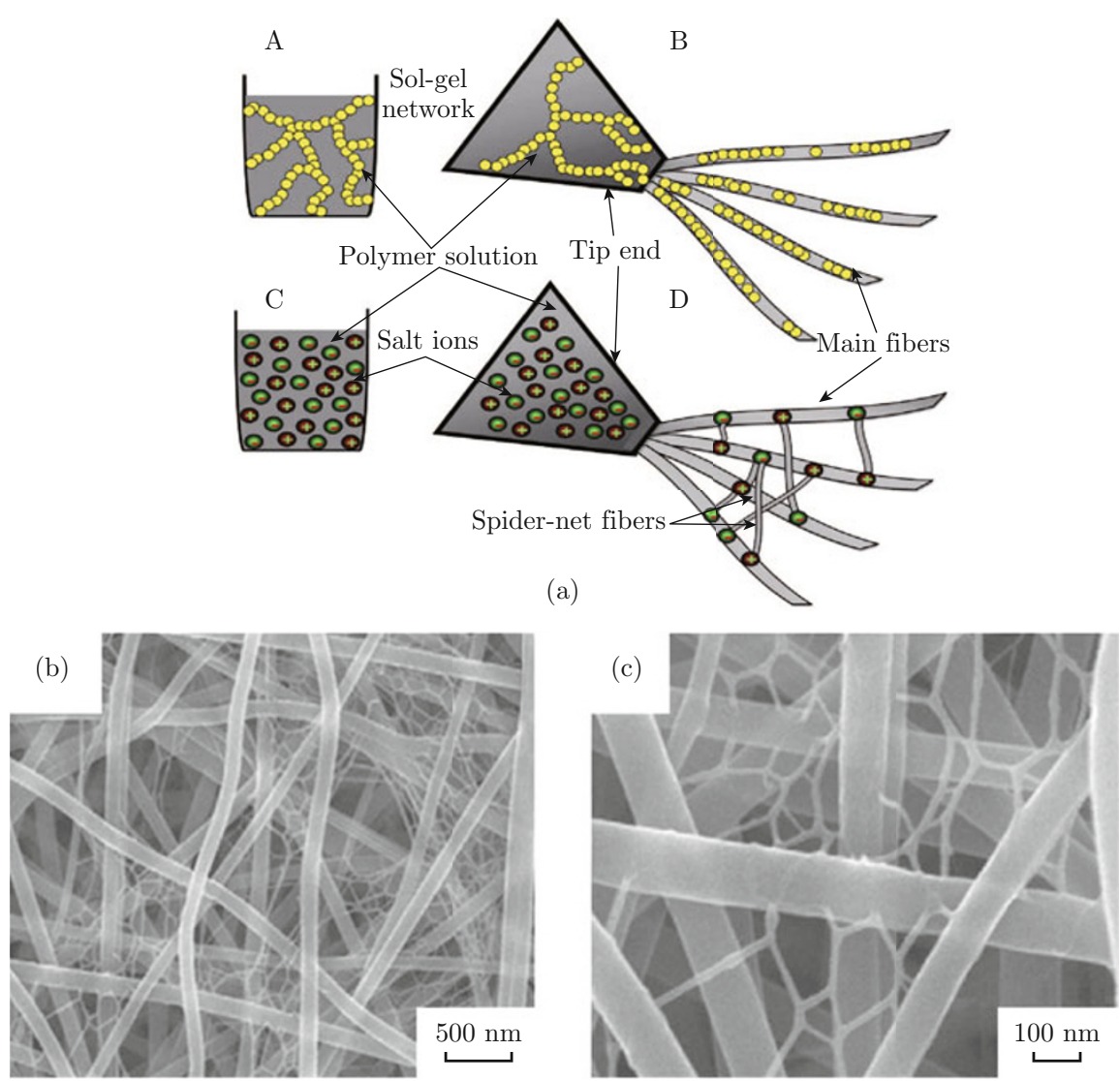

Fig. 5 Schematic diagram showing the mechanism of inorganic salt addition for the spider-net nanofibers (a) and the FE-SEM images of nylon-6 with $\mathrm{H}_{2} \mathrm{PtCl}_{6}$ salt ((b),(c)). (Reprinted from [8] with the permission from Elsevier). 

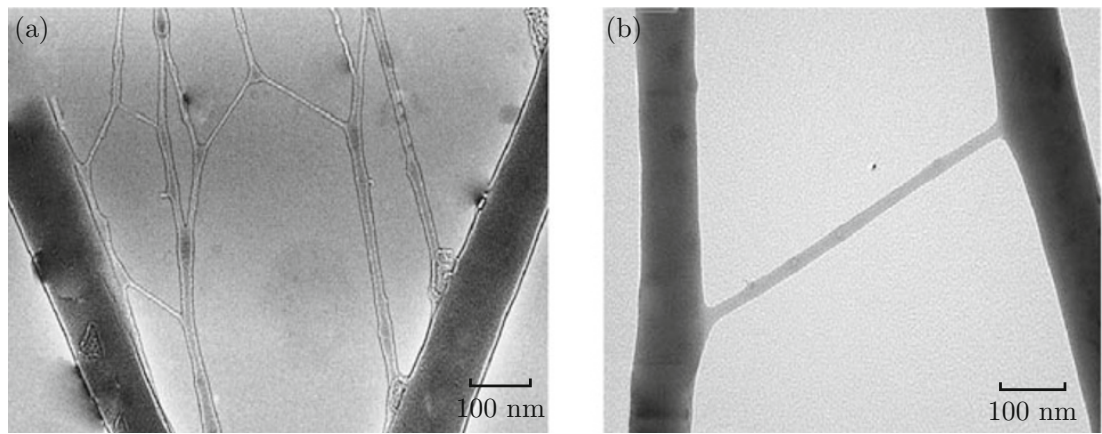

Fig. 6 HR-TEM images of ultrafine nanofibers with $\mathrm{NaCl}$ salt. (Reprinted from [8] with the permission from Elsevier).

\section{Effects of solvents}

To investigate the electrospinnability and the formation of high aspect ratio nanofibers in polyamide6 , various solvents have been employed in the form of single and double solvent systems. The formation of ultrafine polyamide- 6 nanofibers were extensively analyzed using various solvents including formic acid, dichloromethane, acetic acid, chlorophenol, hexafluoroisopropanol and trifluoroacetic acid via single and mixed solvent system. Generally, the polymers bearing reactive functional groups may yield reactions of chemical exchange when they are mixed with solvent, leading to the formation of block, segmented, or random copolymers [99]. The electrospinning of polymer from highly polar solvents leads to smaller fiber diameters. Formic acid has high dielectric constant which can be reflected in the polarity of the molecule. Consequently, the applied electrostatic field can facilitate an increased mass throughput of the solution from the spinneret. The electrical conductivity was dramatically increased when the polyamide- 6 was mixed with formic acid demonstrating that enhanced amounts of free ions in the solution. Well-aligned uniform shaped electrospun polyamide- 6 nanofibers were formed with formic acid. This high surface to volume ratio nanofibers was achieved with the use of a new solvent system that involves an acid base reaction to produce weak complexes which serves to increase the conductivity of the polymer solution. Additionally, the weak complex formed dissociates easily and evaporates along with the solvent during the electrospinning process [104].

The electrospun nanofibers of 22 wt $\%$ polyamide- 6 produced with formic acid and dichloromethane. It was observed that ribbon shaped fibers along with cylindrical fibers. The diameter of ribbon shaped fiber was higher than that of the cylindrical fibers. The reason for the formation of this ribbon shaped fibers is due to the fast evaporation of the solvent during the electrospinning process [105], resulting in the formation of a solid skin that shrinks and collapses upon the evaporation of the remaining solvent.

Electrospinning with two different ratios $3: 2$ and 4:1 of formic acid and acetic acid, respectively, to check for the high aspect ratio nanofibers (Fig. 7). The resulting electrospun fibers were uniform in dimension and had a smooth surface morphology. The high aspect ratio fibers were not strongly bonded with the main fibers. A possible explanation may be due to the lower dielectric constant and surface tension with those of formic acid. Both solvent systems were successfully able to produce electrospun composites. However, the uniformity of the fiber was improved and the size of the fiber was slightly increased in the solvent combination of formic acid and acetic acid.

Electrospun nanofibers of $22 \mathrm{wt} \%$ polyamide- 6 produced with formic acid and chlorophenol can also be produced very less amount of high aspect ratio nanofibers. The diameter of the main fibers was slightly increased than that in the previous cases. However, the chlorophenol single solvent system can also be used as good solvent for polyamide-6. However, this solvent system did not produce high aspect ratio nanofibers in polyamide- 6 owing to the very low conductivity ( 0.042 $\mathrm{mS} / \mathrm{m})$. It is possible to obtain uniform nanofibers by adjusting experimental parameters such as the solution concentration, applied voltage, etc. Hexafluoroisopropanol is an acidic alcohol and due to its strong hydrogen bonding properties it can be used as a solvent for many different kinds of polymers. Using this solvent, though it was electrospinnable, the resulting polyamide- 6 fibers were observed to be thicker. This result is attributed to the high density of this solvent, which tend to a high viscosity and, consequently, the electrospun fibers showed the highest diameter values. The electrospun polyamide- 6 nanofibers from hexafluoroisopropanol solvent system had more point-bonded junctions. We could not obtain the high aspect ratio nanofibers for this solvent system. Trifluoroacetic acid is the simplest stable perfluorinated carboxylic acid chemical compound. It is a strong carboxylic acid due to the influence of the electronegative trifluoromethyl group. Trifluoroacetic acid is more acidic than acetic acid. Surprisingly, we did not observe any nanofibers using this solvent. A likely explanation may be due to the strong acidic nature of trifluoroacetic acid that caused a drastic reduction in the molecular weights 

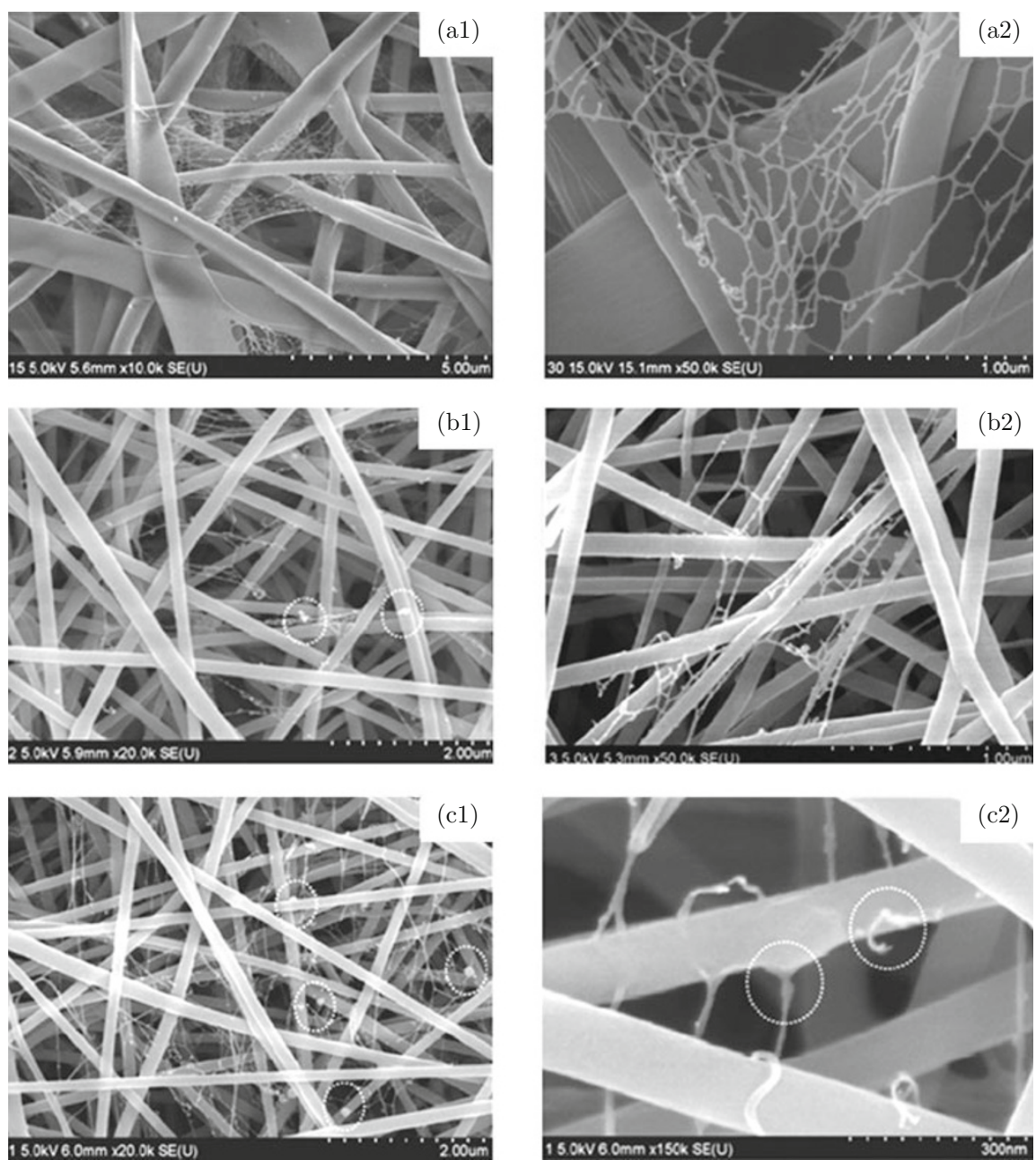

Fig. 7 FE-SEM images of electrospun polyamide-6 nanofibers produced with (a) formic acid + dichloromethane (3:2), (b) formic acid + acetic acid (3:2) and (c) formic acid + acetic acid (4:1); (1) low magnification and (2) high magnification. (Reprinted from [64] with the permission from Springer).

Table 1 Properties of electrospun ultrafine polymer nanofibers

\begin{tabular}{|c|c|c|c|c|}
\hline Materials & Solvent & Key Factor & $\begin{array}{l}\text { Ultrafine Nanofiber } \\
\text { Diameter }(\mathrm{nm})\end{array}$ & Reference \\
\hline Polyamide 6 & Formic acid & Applied voltage & $8-40$ & 65 \\
\hline Polyamide 6 & Formic acid + Dichloro Methane $(3: 2)$ & Solvent & $13-34$ & 64 \\
\hline Polyamide 6 & Formic acid + acetic acid $(3: 2)$ & Solvent & $8-38$ & 64 \\
\hline Polyamide 6 & Formic acid + acetic acid $(4: 1)$ & Solvent & $8-32$ & 64 \\
\hline Polyamide 6 & Formic acid + Chlorophenol $(1: 1)$ & Solvent & $8-30$ & 64 \\
\hline Polyamide 6/Chitosan & Formic acid & Solvent & $20-40$ & 64 \\
\hline Polyamide 6/Lecithin & Formic acid & Solvent & $10-30$ & 64 \\
\hline PAN/nylon 6 & Formic acid + acetic acid $(4: 1)$ & Monomer & 20 & 108 \\
\hline PAA/Nylon 6 & Formic acid & Monomer & 19 & 72 \\
\hline Nylon 6 & Formic acid + acetic acid $(4: 1)$ & Inorganic salt & $10-30$ & 8 \\
\hline $\mathrm{PU}$ & $\mathrm{THF}+\mathrm{DMF}$ & Inorganic salt & $10-30$ & 8 \\
\hline PVA & Water & Inorganic salt & $10-30$ & 8 \\
\hline PAA & Water + ethanol & Humidity, applied voltage & $10-20$ & 71 \\
\hline Nylon 6 & Formic acid & Humidity, applied voltage & $10-20$ & 71 \\
\hline $\mathrm{PVA} / \mathrm{ZnO}$ & Water + zinc acetate solution & Metal oxide & $25-50$ & 71 \\
\hline Nylon $6 / \mathrm{TiO}_{2}$ & Formic acid + acetic acid $(4: 1)$ & Metal oxide & $30-50$ & 109 \\
\hline
\end{tabular}

Abbreviation in Table 4: PAN (poly acrylonitrile); PAA (polyacrylic acid); PU (polyurethane); PVA (poly vinyl alcohol); THF (tetrahydrofuran); DMF (N,N-dimethylformamide); $\mathrm{ZnO}$ (zinc oxide). 
owing to the rapid increase of viscosity in the solution [96]. As a result of that the electrospinnability of polyamide- 6 with trifluoroacetic acid was not possible which led to the formation of thin film like structure.

Table 1 summarizes the role of process parameters on the formation of ultrafine polymeric nanofibers. From these results, it is interesting to note that wellaligned uniform electrospun nanofibers and high aspect ratio nanofibers (diameters in the range from 8 to $35 \mathrm{~nm}$ ) of polyamide- 6 can be produced from formic acid and its mixture solutions. However, the other single solvent system (namely, chlorophenol and hexafluoroisopropanol) except trifluoroacetic acid can also be used as solvents for polyamide- 6 , in which the expected high aspect ratio nanofibers were not produced. It is believed that the formation of high aspect ratio nanofibers in polyamide- 6 can strongly depend on the poly-electrolytic behavior in the solvent. As a result, the electrical conductivity of the polymer solution was increased due to the formation of enormous free ions. By changing the polymer concentration and solvent ratio one can obtain high aspect ratio nanofibers with uniform diameters.

\section{Effect of humidity}

Bin Ding et al. [71] have recently reported that the formation of the nanowebs of poly(acrylic acid) (PAA) and nylon- 6 is considered to be due to the electrically forced fast phase separation of the charged droplets which move at high speed between the capillary tip and the collector. During electrospinning process, the forces acting on the charged droplet during the high speed flight in the electric field. The forces include electrostatic force, drag force, gravity, Coulombic repulsion force, surface tension and viscoelastic force. The electrostatic force carried the charged droplet from the capillary tip to the collector. The drag force acted on the surrounding air and charged droplet moving at high speed. Also, the deformation of the droplets into films was attributed to the drag force. The Coulombic repulsion force tried to expand the droplet. The surface tension and viscoelastic forces led to the contraction of the charged droplet [106]. The electric field could be increased by increasing the applied voltage at a constant distance. Consequently, the electrostatic and Coulombic repulsion forces of the charged droplet were reinforced with increase in the strength of the electric field. The increased electrostatic force further accelerated the movement of the charged droplet, which led to an increased drag force. The distortion and expansion of charged droplet from a spherical-like to a spindle-like structure in the electric field during electrospraying was reported by Grimm and Beauchamp [107]. The additional expansion could have happened when the Coulombic repulsion and drag forces increased along with the electric field from droplets. Moreover, the increased radial charge repulsion force also had a tendency to expand the charged films. As a result, the deformation of charged droplet was strongly affected by the electric field.

\section{Effect of monomer}

Parajuli and coworkers [72] have synthesized poly(acrylic acid) monomer in a viscous supporting nylon solution was polymerized and fabricated simultaneously via an electrospinning process (Scheme 1). The acrylic acid polymerization is achieved via formic acid reduction during the electrospinning process. Typically, formic acid loses a proton in the acrylic acid solution because of the high acidity. Deprotonated formic acid splits into $\mathrm{CO}_{2}$ and a hydride ion, which works as a reducing agent $[108,109]$. If the hydride ion attacks a $\beta$ carbon of an $\alpha, \beta$ unsaturated carbonyl monomer (acrylic acid), group-transfer polymerization can be initiated [110]. In the performance of polymerization via electrospinning, it is difficult to control all parameters, such as the pressure, temperature, and concentration; however, there is sufficient control to allow for the investigation of structural, chemical, and physical modifications of electrospun mats. In an another study, Park et al. [111] have reported that the poly(acrylonitrile) (PAN) nanofiber web interpenetrated nylon- 6 nanofiber supporters by electrospinning of an acrylonitrile (AN)/nylon-6 solution.

\section{Effect of metal oxide}

Mixing of two materials at the nanoscale can form a unique and effective multifunctional nanocomposite material. It was reported that the $\mathrm{TiO}_{2}$ nanoparticles can form spider-net like electrospun nylon-6 fiber mats, which can lead to a remarkable increase in the number of reactive sites with a corresponding improvement in hydrophilicity, photocatalytic and antimicrobial activity $[112,113]$. It was also reported that the preparation of a novel nylon- $6 / \mathrm{TiO}_{2}$ organic-inorganic nanocomposite material in the form of an electrospun mat, containing two distinct types of fibers (nano and sub nanosized) loaded with $\mathrm{TiO}_{2}$ nanoparticles, with superior mechanical strength, high hydrophilicity, and good antimicrobial as well as UV blocking ability. This spidernet like nano-structure mat with antimicrobial and hydrophilic properties (antifouling effect) would have great potentiality for water filter applications. Furthermore, the good UV blocking capacity and improved mechanical strength of electrospun mat is highly beneficial for different kinds of protective clothing. Moreover, our research group have recently reported that the electrical characterization of the polyamide- $6 / \mathrm{TiO}_{2}$ composite nanofibers showed a pure resistive behavior of the conductive nanofibers and a good stability of the as-spun nanostructures [114,115]. This significant 


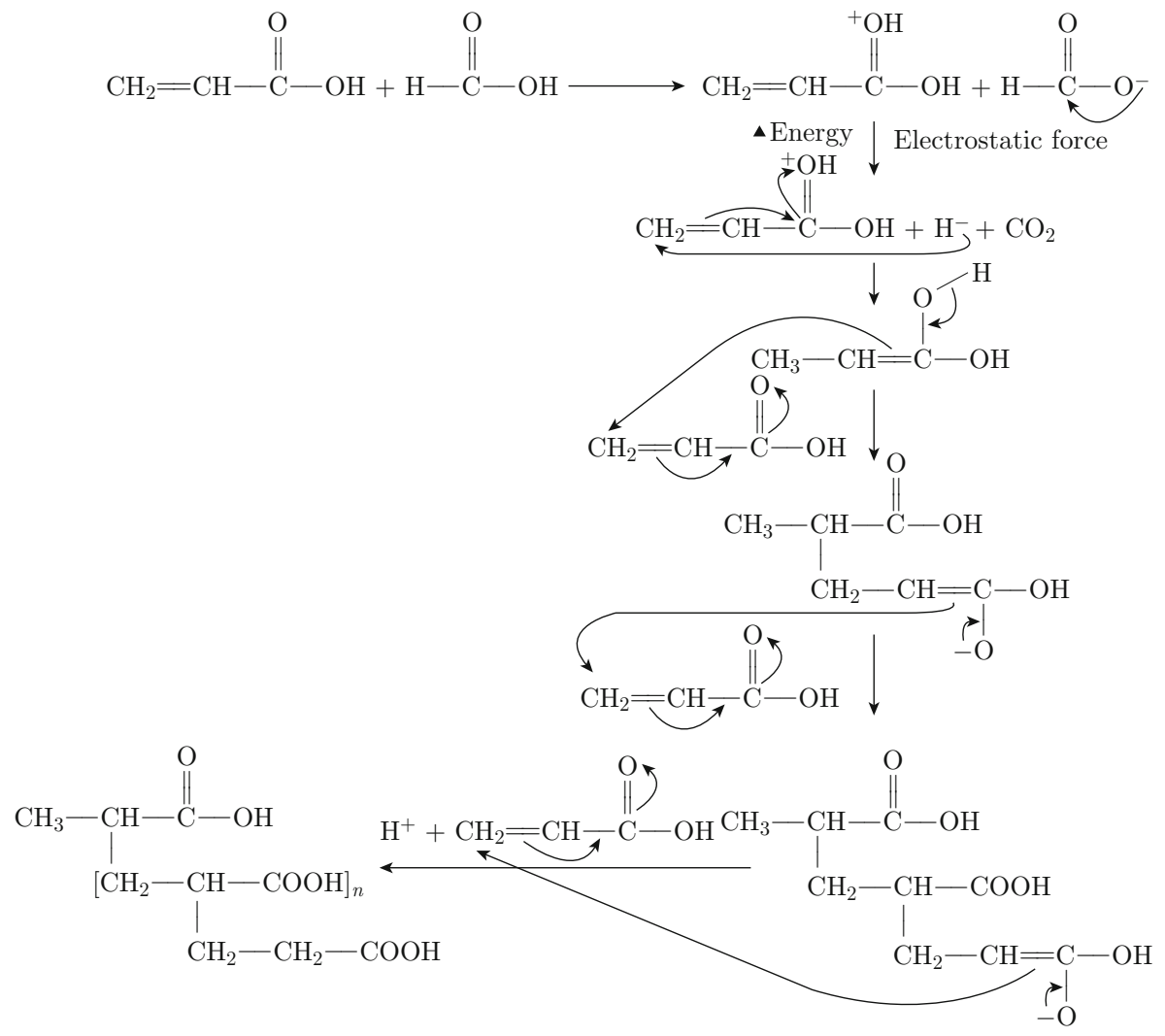

Scheme 1 Synthesis of poly(acrylic acid) monomer (Reprinted from [72] with the permission from ACS)

enhancement of electrical properties of these polyamide- 6 composite nanofibers can be utilized for quite promising future nanotechnological applications. This observation will continue to drive researchers toward developing future organic based nanodevices.

In another study, it was describe that a novel method to prepare superhydrophobic $\mathrm{ZnO}$ surfaces by the combination of electrospinning technique and a wet chemical route, which is simple and straightforward [68]. It shows a very good experimental reproducibility and can produce nanostructured surfaces at a large scale. Here, the fabrication of super-hydrophobic $\mathrm{ZnO}$ surfaces is composed of two steps. First, the $\mathrm{ZnO}$ nanostructured surface was formed by the calcination of composite nanofibrous films which obtained via electrospinning. Then the as-prepared rough surface was modified by fluoroalkylsilane coating to obtain a super-hydrophobic surface. Additionally, the wettability of pure polymer and composite nanofibrous film surfaces was also investigated.

\section{Application of ultrafine polyamide-6 nanofiber membranes}

Nanostructures are attractive materials for nanoscience studies as well as nanotechnological ap- plications. The unique feature of elestrospun ultrafine nanofiber, compared to other low dimensional systems, are that have very small diameters, extremely long length, large surface area per unit mass and small pore size. The attractive properties of $1 \mathrm{D}$ system arise from their unique chemistry and physics. Nanostructured nanofibers systems are promising for diverse applications, such as the transport and targeted release of drugs and active agents in organisms, tissue engineering, the surface modification of implants, and wound healing.

Presently, most patents on electrospinning are focused on applications rather than on new materials or on new processes. Commercialized applications were accomplished by several companies worldwide in specialty filters (air filtration, coalescence filters) with an increasing market in the coming years. Tissue engineering is going to be another successful field of applications for electrospun biodegradable nanofibers (e.g., PLA) because cells including stem cells grow well on these nanofibers. An additional plus is the large potential for loading of electrospun nanofibers by biologically active agents ranging from salts to drugs and proteins. Protective clothing, in particular in combination with special reagents, is expected to enhance the performance of military protective clothing. The main focus here is on trapping of aerosols of chemical and biological warfare agents. 

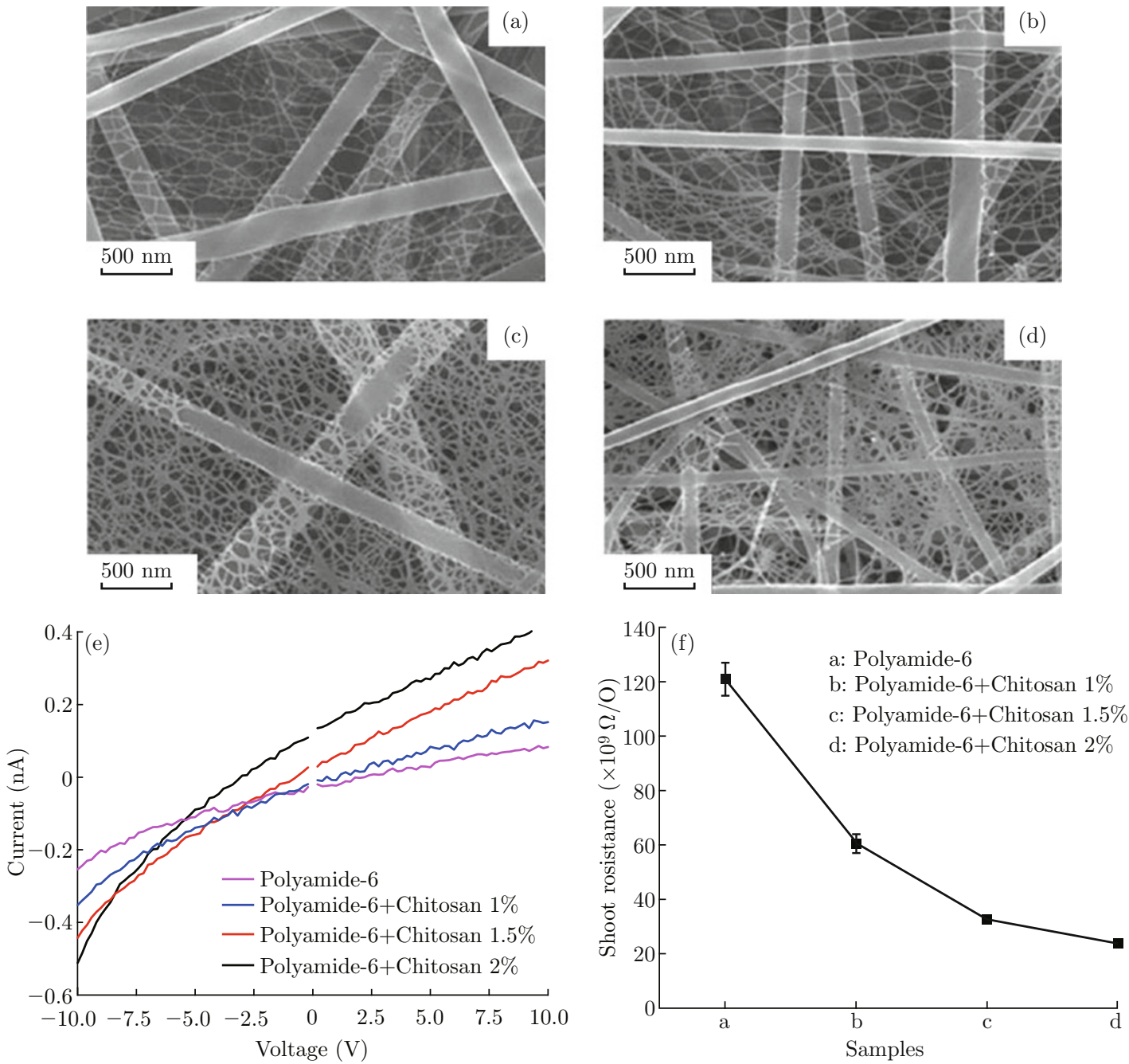

Fig. 8 FE-SEM image of electrospun polyamide-6/chitosan nanofibers with different weight percentage of chitosan (a) 0; (b) 1 ; (c) 1.5 and (d) $2 \mathrm{wt} \%$. I-V characteristics of electrospun polyamide-6/chitosan composite nanofibers with different wt\% of chitosan ((e),(f)). (Reprinted from [70] with the permission from Elsevier).

\section{Sensors}

The remarkable high surface area-to-volume ratio, small diameter and high porosity bring electrospun nanofibers highly attractive to ultrasensitive sensors and increasing importance in many technological applications. The formation of denser ultrafine nanofibers with addition of chitosan content showed a great improvement in I-V characteristics [70]. For example, the excess chitosan possibly enveloped the ultrafine fiber networks in between polyamide-6/chitosan composite nanofibers with different concentration of chitosan can be enhanced the electrical pathways (Fig. 8). Further, a significant enhancement of the electrical conductance was observed for the samples of composite nanofibers than that of the pristine polyamide- 6 nanofibers. This observation can be explained by the charge compensation of the major charge carriers in the composite nanofibers. Consequently, the electrical conductivity of the polyamide- $6 /$ chitosan composite nanofibers was prepared with 2 wt\% chitosan exhibited the maximum current of $0.4 \mathrm{pA}$. It is also believed that the enhanced porosity of these composite nanofibers can be utilized for the biosensor applications with improved performance and sensitivity.

Recently, Wang et al. [116] have demonstrated a simple and straightforward strategy of depositing a nanostructured complex, based on a polyethyleneimine functionalized polyamide- 6 nanofibers, on a quartz crystal microbalance sensor for humidity detection (Fig. 9). The polyamide- 6 nanofiber substrate, comprising common electrospun nanofibers and spider-web-like nanonets fabricated by a versatile electrospinning process, exhibits several fundamental characteristics, such as a remarkable specific surface area, high open porosity and good interconnectivity. The frequency changes by approximately three orders of magnitude with relative humidity varying from $2 \%$ to $95 \%$. Finally, they presented the polyethyleneimine functionalized polyamide6 nanofibers with relatively small hysteresis and longterm stability. 

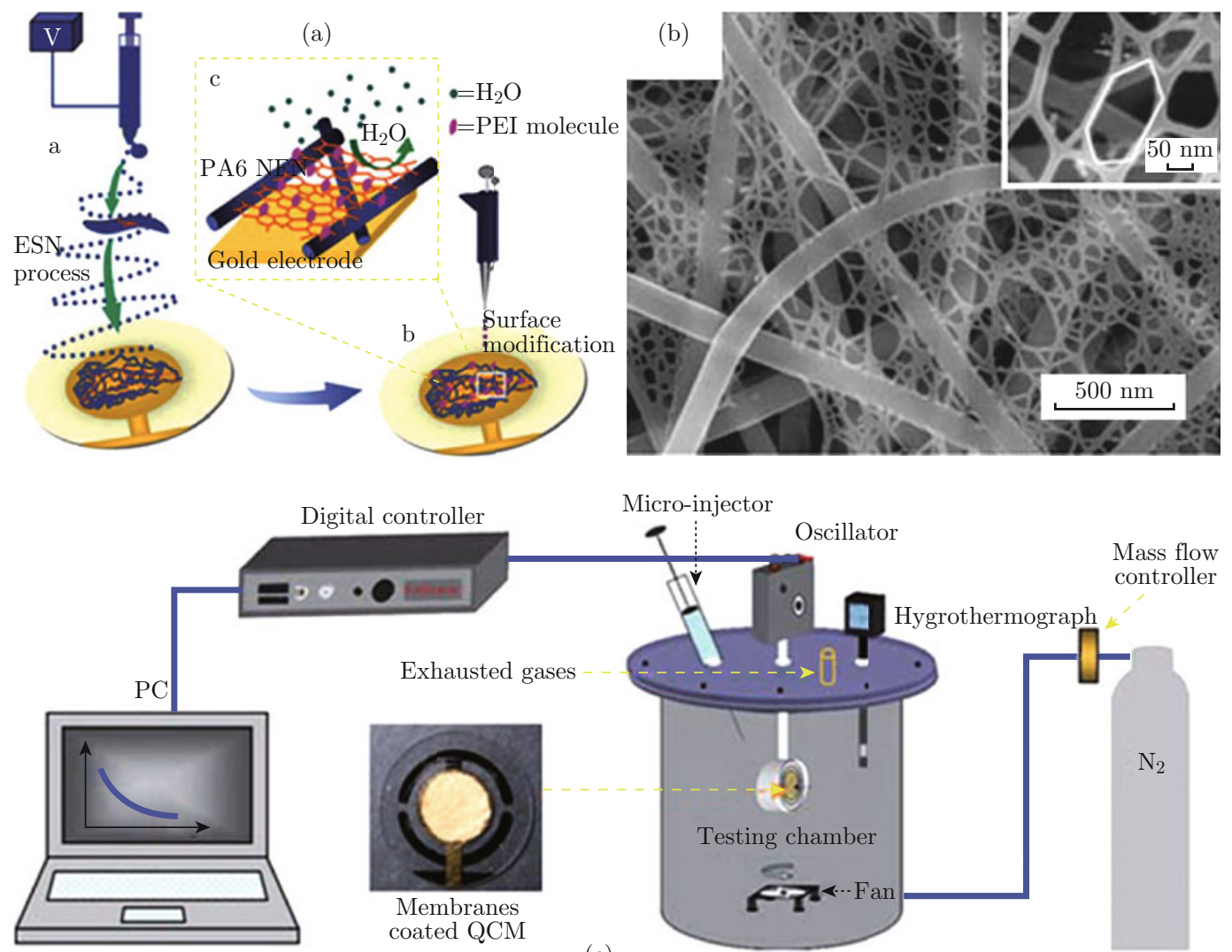

(c)

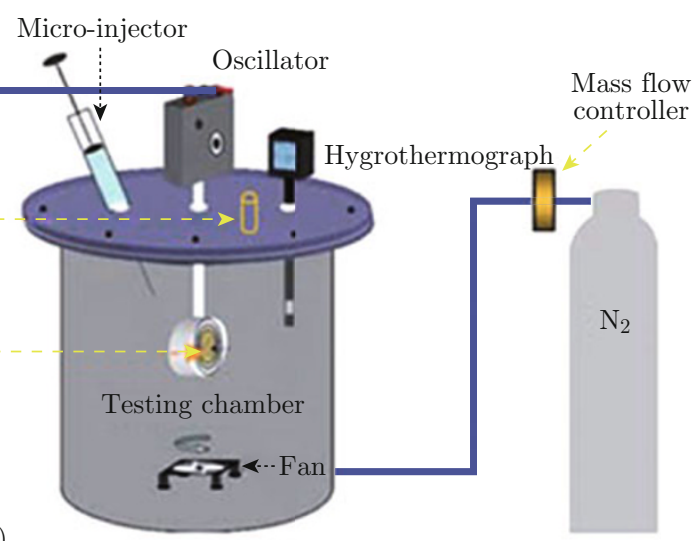

Fig. 9 Highly sensitive humidity sensors based on electro-spinning/netting a polyamide-6 nanofibers. (a) Schematic diagram illustrating the preparation of sensing coatings on quartz crystal microbalance. (b) FE-SEM image of polyamide-6 nanofiber membranes. (c) Schematic diagram illustrating a gas testing system for relative humidity detection. (Reprinted from [116] with the permission from RSC).

\section{Cell culture scaffolds}

Polyamide-6 is commercially important, and one of the prominent members of the polyamides which has polymorphic, biodegradable, biocompatible and synthetic polymeric material with good mechanical and physical properties. Recently, we have reported one step synthesis of polyamide-6/lecithin homogenously blended nanofibers via electrospinning for osteoblastic cell culture applications [117]. These as-spun polyamide-6/lecithin nanofibers exhibited a smooth surface and uniform diameters along their lengths. The fine nanofiber structure resulted in a large surface areato-volume ratio and interconnected porosity (Fig. 10). Human osteoblast cells were utilized for this analysis. The cells spread over the scaffold fibers, linked with fibers by cytoplasmic extensions (Fig. 11). In tissue culture, cell-based tissue engineering is one of the principle research areas. The ability of the cell to regenerate bone was developed by in vitro cell expansion method (Fig. 12). These results suggested the polyamide-6/lecithin composite nanofibers can be utilized for bone regeneration if we increase the mechanical strength of the scaffold by layer-by-layer deposition of polymer fibers. However, these polyamide-6/lecithin composite nanofibers can be used to engineer living tissue in vitro for subsequent transplantation to the defect sites. In an another study, the same authors have reported that the formation of high aspect ratio nanofibers in polyamide- 6 /chitosan composites and the in vitro cytotoxic analysis based on the peculiar spidernet like structures [118].

\section{Photocatalytic membranes}

The efficiency of free $\mathrm{TiO}_{2}$ nanoparticles in a polymer matrix is almost same, which confirms that the surface area of the $\mathrm{TiO}_{2}$ nanoparticles does not significantly decrease upon the incorporation of the nanoparticles into the polymer fiber [112]. For this purpose, a used fiber mat was kept in water for 7 days and reused after washing five times with distilled water. Then the photo degradation of methylene blue dye was carried out under the same conditions as before. The efficiency of the reused mat is nearly similar to that of the initially used mat. A slight decrease in the photocatalytic efficiency of the reused mat was observed, which may be due to the deposition of byproduct particles on the surfaces of the NPs. Initially, the efficiency of the reused nanofibers was less than the initially used one, but after 
some time it was nearly equal, which indicates the presence of some foreign particles in the used mat. Moreover, the change in shape of the Ag nanoparticles due to the intense solar radiation may be the cause of decreased photocatalytic efficiency.

\section{Multi-component textile material}

The mixing of these two materials at the nanoscale can form a unique and effective multifunctional nanocomposite textile material. It is expected that the $\mathrm{TiO}_{2}$ nanoparticles can form spider-net like electrospun nylon-6 fiber mats, which can lead to a remarkable
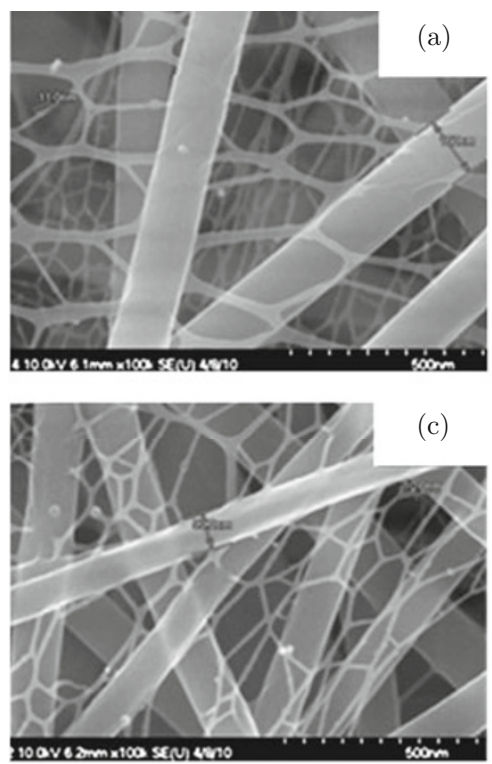

increase in the number of reactive sites with a corresponding improvement in hydrophilicity, photocatalytic and antimicrobial activity. This spider-net like nanostructure mat with antimicrobial and hydrophilic properties (antifouling effect) would have great potentiality for water filter applications [113]. Furthermore, the good UV blocking capacity and improved mechanical strength of electrospun mat is highly beneficial for different kinds of protective clothing.

\section{Concluding remarks}

Polymer nanofibers with high aspect ratio structure
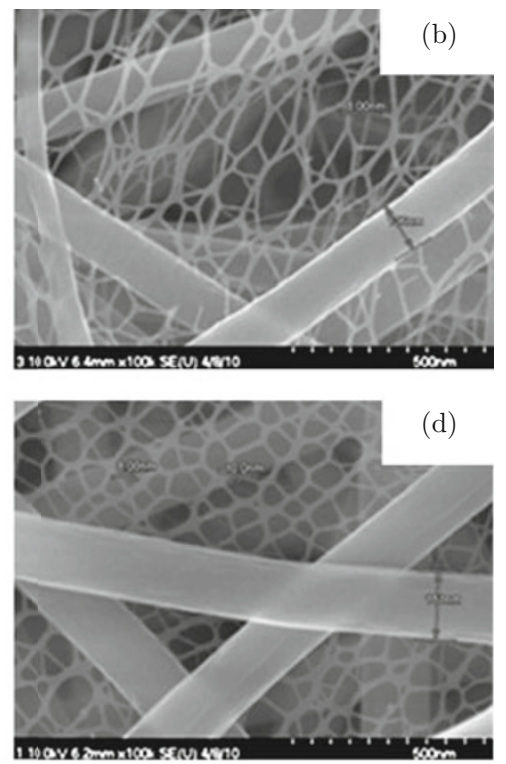

Fig. 10 FE-SEM images of electrospun polyamide-6/lecithin nanofibers with different wt.\% of lecithin (a) 0; (b) 1; (c) 3 and (d) $5 \mathrm{wt} \%$. (Reprinted from [117] with the permission from Elsevier).
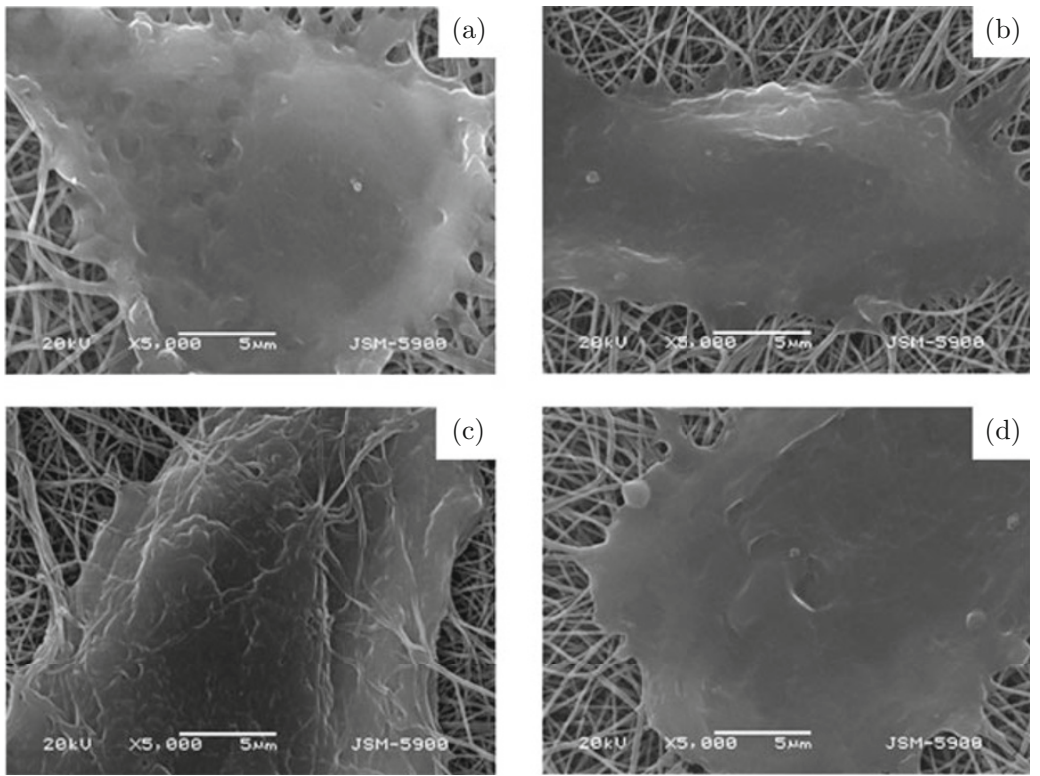

Fig. 11 SEM image of the cell growth on electrospun polyamide-6/lecithin nanofibers containing different concentration of lecithin with (a) 0; (b) 1; (c) 3 and (d) 5 wt\%. (Reprinted from [117] with the permission from Elsevier). 


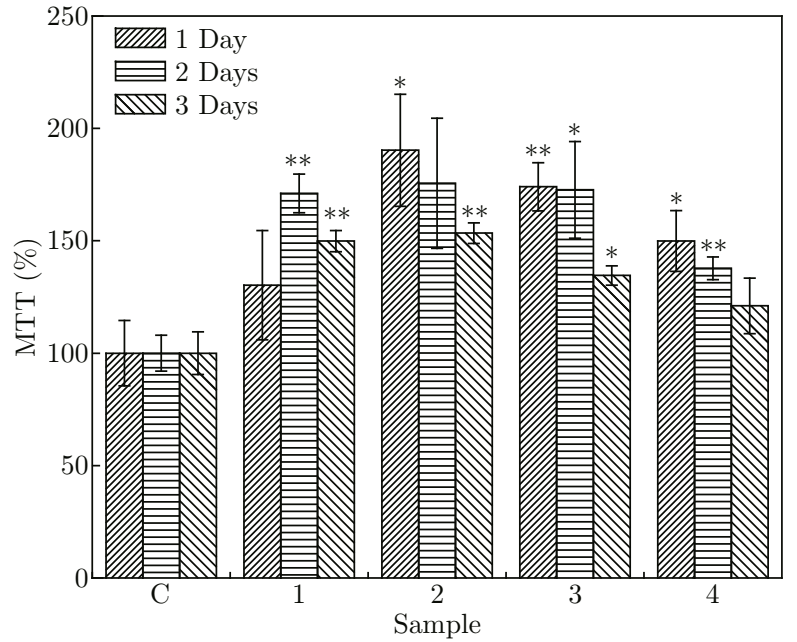

(a)

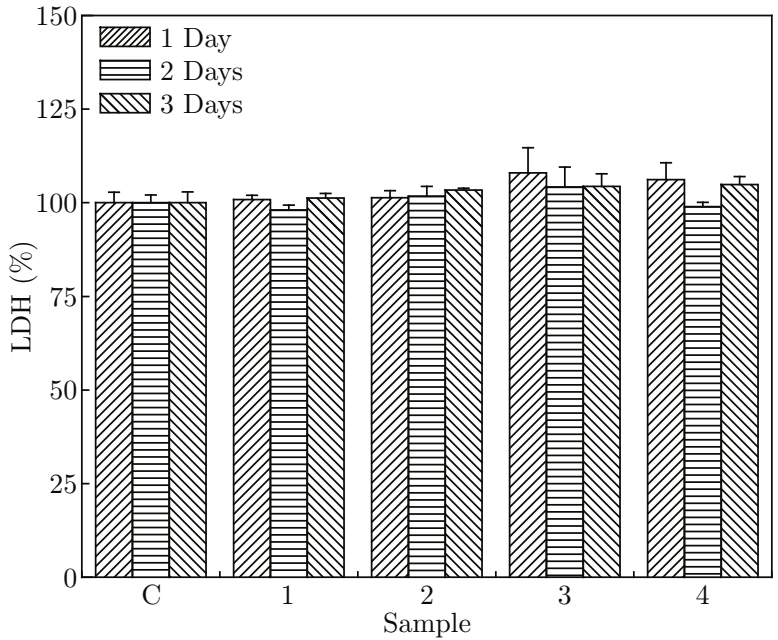

(b)

C-Control, 1-PA-6+Lecithin $0 \mathrm{wt} \%, \quad 2-\mathrm{PA}-6+$ Lecithin $1 \mathrm{wt} \%, \quad 3-\mathrm{PA}-6+$ Lecithin $3 \mathrm{wt} \%, \quad 4-\mathrm{PA}-6+$ Lecithin $5 \mathrm{wt} \%$

Fig. 12 Cell growth measurement of (a) MTT and (b) LDH on electrospun Polyamide-6/lecithin nanofibers with different lecithin concentration of $0,1,3$ and $5 \mathrm{wt} \%$. Cell viability was determined in accordance with LDH and MTT test. (Reprinted from [117] with the permission from Elsevier).

were successfully produced by electrospinning technique. Electrospinning has potential advantages in cost, simplicity and innovation in preparing polymer nanofibers with controllable nanostructures for the industrial and biological applications. The large surface area to volume ratio polyamide- 6 and their composite nanofibers with diameters less than $50 \mathrm{~nm}$ can be achieved. This review collectively summarizes the process feasibility for the formation of ultrafine polymeric nanofibers with variety of parameters such as with and without additives. Further, we explored the prominent application point of view with these ultrafine polyamide- 6 based nanofibers. We believe that this topical review will definitely open new directions as per the nanotechnological applications are concerned. We anticipate that the continuous research activities on these ultrafine polymeric nanofibers can significantly progress towards the rapid improvements based on the next generation nano-device applications.

\section{Acknowledgements}

This research was financially supported by the Ministry of Education, Science Technology (MEST) and National Research Foundation of Korea (NRF) through the Human Resource Training Project for Regional Innovation (2012H1B8A2025931). This work was also supported by the National Research Foundation of Korea (NRF) grant funded by the Korea government (MEST) (No. 2012R1A2A2A01046086).

\section{References}

[1] A. Greiner and J. H. Wendoff, "Electrospinning:
A fascinating method for the preparation of ultrathin fibers", Angew. Chem. Int. Ed. 46(30), 5670-5703 (2007). http://dx.doi.org/10.1002/ anie. 200604646

[2] V. N. T. K. Satyanarayana, A. S. Karakoti, D. Bera and S. Seal, "One dimensional nanostructured materials", Prog. Mater. Sci. 52(5), 699-913 (2007). http://dx.doi.org/10.1016/j.pmatsci.2006.08. 001

[3] K. S. Shankar and A. K. Raychaudhuri, "Fabrication of nanowires of multicomponent oxides: Review of recent advances", Mater. Sci. Eng. C 25(5-8), 738-751 (2005). http://dx.doi.org/10.1016/j.msec. 2005. 06.054

[4] C. N. R. Rao and A. Govindaraj, "Synthesis of inorganic nanotubes", Adv. Mater. 21(42), 42084233 (2009). http://dx.doi.org/10.1002/adma. 200803720

[5] M. H. Al-Saleh and U. Sundararaj, "A review of vapor grown carbon nanofiber/polymer conductive composites", Carbon 47(1), 2-22 (2009). http://dx. doi.org/10.1016/j. carbon. 2008.09.039

[6] J. Y. Lin, D. Ding, J. Y. Yu and Hsieh, "Direct fabrication of highly nanoporous polystyrene fibers via electrospinning", ACS Appl. Mater. Interfaces 2(2), 521-528 (2010). http://dx.doi.org/10.1021/ am900736h

[7] Y. Zhu, D. Y. Yang and H. W. Ma, "One-step fabrication of porous polymeric microcage via electrified jetting", Nanoscale 2(6), 910-912 (2010). http://dx. doi.org/10.1039/CONR00081G

[8] N. A. M. Barakat, M. A. Kanjwal, F. A. Sheikh and H. Y. Kim, "Spider-net within the N6, PVA and $\mathrm{PU}$ electrospun nanofiber mats using salt addition: Novel strategy in the electrospinning process", Polymer 50(18), 4389-4396 (2009). http://dx.doi.org/ $10.1016 / j$. polymer. 2009.07.005 
[9] K. Sarkar, C. Gomez, S. Zambrano, M. Ramirez, E. Hoyos, H. Vasquez and K. Lozano, "Electrospinning to forcespinning", Mater. Today 13(11), 12-14 (2010). http://dx.doi.org/10.1016/ S1369-7021 (10)70199-1

[10] Y. Hong, X. Chen, X. Jiang, H. Fan, B. Guo, Z. Gu and X. Zhang, "Preparation, bioactivity, and drug release of hierarchical nanoporous bioactive glass ultrathin fibers", Adv. Mater. 22(6), 754-758 (2010). http://dx.doi.org/10.1002/adma. 200901656

[11] R. Gopal, S. Kaur, Z. Ma, C. Chan, S. Ramakrishna and T. Matsuura, "Electrospun nanofibrous filtration membrane", J. Membr. Sci. 281(1-2), 581586 (2006). http://dx.doi.org/10.1016/j.memsci. 2006.04 .026

[12] W. W. F. Leung, C. H. Hung and P. T. Yuen, "Effect of face velocity, nanofiber packing density and thickness on filtration performance of filters with nanofibers coated on a substrate", Sep. Purif. Technol. 71(1), 30-37 (2010). http://dx.doi.org/10. 1016/j.seppur.2009.10.017

[13] K. Desai, K. Kit, J. Li, P. M. Davidson, S. Zivanovic and $\mathrm{H}$, Meyer, "Nanofibrous chitosan nonwovens for filtration applications", Polymer 50(15), 3661-3669 (2009). http://dx.doi.org/10.1016/j. polymer.2009.05.058

[14] S. Chigome, G. Darko and N. Torto, "Electrospun nanofibers as sorbent material for solid phase extraction", Analyst 136, 2879-2889 (2011). http://dx. doi.org/10.1039/C1AN15228A

[15] P. W. Gibson, H. L. S. Gibson and D. Riven, "Electrospun fiber mats: transport properties", AIChE 45(1), 190-195 (1999). http://dx.doi.org/10.1002/ aic. 690450116

[16] H. S. Gibson, P. Gibson, K. Senecal, M. Sennett, J. Walker and M. Yeomans, "Protective textile materials based on electrospun nanofibers", J. Adv. Mater. 34(3), 44-55 (2002).

[17] P. Gibson, H. S. Gibson and D. Rivin, "Transport properties of porous membranes based on electrospun nanofibers", Colloids Surf. A Physicochem. Eng. Aspect 187-188(31), 469-481 (2001). http://dx.doi. org/10.1016/S0927-7757(01)00616-1

[18] B. Ding, M. Wang, X. Wang, J. Yu and G. Sun, "Electrospun nanomaterials for ultrasensitive sensors", Mater. Today 13(11), 16-27 (2010). http:// dx.doi.org/10.1016/S1369-7021(10)70200-5

[19] X. Wang, B. Ding, J. Yu, Y. Si, S. Yang and G. Sun, "Electro-netting: Fabrication of two-dimensional nano-nets for highly sensitive trimethylamine sensing", Nanoscale 3, 911-915 (2011). http://dx.doi. org/10.1039/CONR00783H

[20] B. Ding, M. Wang, J. Yu and G. Sun, "Gas sensors based on electrospun nanofibers", Sensors 9(3), 1609-1624 (2009). http://dx.doi.org/10. $3390 /$ s90301609

[21] Z. Ouyang, J. Li, J. Wang, Q. Li, T. Ni, X. Zhang, H. Wang, Q. Li, Z. Su and G. Wei, "Fabrication, characterization and sensor application of electro- spun polyurethane nanofibers filled with carbon nanotubes and silver nanoparticles", J. Mater. Chem. B 1, 2415-2424 (2013). http://dx.doi.org/10.1039/ C3TB20316F

[22] Y. Y. Lv, W. Xu, F. W. Lin, J. Wu and Z. K. $\mathrm{Xu}$, "Electrospun nanofibers of porphyrinated polyimide for the ultra-sensitive detection of trace TNT", Sensors and Actuators B 184(31), 205-211 (2013). http://dx.doi.org/10.1016/j.snb.2013.04.094

[23] J. Yang, J. Yu, J. Fan, D. Sun, W. Tang and X. Yang, "Biotemplated preparation of CdS nanoparticles/bacterial cellulose hybrid nanofibers for photocatalysis application", J. Haz. Mater. 189(12), 377-383 (2011). http://dx.doi.org/10.1016/j. jhazmat. 2011.02.048

[24] S. S. Lee, H. Bai, Z. Liu and D. D. Sun, "Novel-structured electrospun $\mathrm{TiO}_{2} / \mathrm{CuO}$ composite nanofibers for high efficient photocatalytic cogeneration of clean water and energy from dye wastewater", Water Res. 47(12), 4059-4073 (2013). http:// dx.doi.org/10.1016/j. watres. 2012.12.044

[25] C. Drew, X. Wang, K. Senecal, H. S. Gibson, J. He and J. Kumar, "Electrospun photovoltaic cells", J. Macromol. Sci. Pure Appl. Chem. 39(10), 1085-1094 (2002). http://dx.doi.org/10.1081/MA-120014836

[26] G. Verreck, I. Chun, J. Rosenblatt, J. Peeters, A. V. Dijck and J. Mensch, "Incorporation of drugs in an amorphous state into electrospun nanofibers composed of a water-insoluble, nonbiodegradable polymer", J. Control. Rel. 92(3), 349-360 (2003). http: // dx.doi.org/10.1016/S0168-3659(03)00342-0

[27] M. S. Khil, D. I. Cha, H. Y. Kim, I. S. Kim and N. Bhattarai, "Electrospun nanofibrous polyurethane membrane as wound dressing", J. Biomed. Mater. Res. B Appl. Biomater. 67B(2), 675-679 (2003). http://dx.doi.org/10.1002/jbm.b.10058

[28] A. Celebioglu, O. C. O. Umu, T. Tekinay and T. Uyar, "Antibacterial electrospun nanofibers from triclosan/cyclodextrininclusion complexes", Coll. Surf. B: Biointerfaces, in press. http://dx.doi.org/10. 1016/j.colsurfb. 2013.10.029

[29] A. Sharma, A. Gupta, G. Rath, A. Goyal, R. B. Mathura and S. R. Dhakate, "Electrospun composite nanofiber-based transmucosal patch for anti-diabetic drug delivery", J. Mater. Chem. B 1, 3410-3418 (2013). http://dx.doi.org/10.1039/C3TB20487A

[30] J. A. Matthews, G. E. Wnek, D. G. Simpson and G. L. Bowlin, "Electrospinning of collagen nanofibers", Biomacromolecules 3(2), 232-238 (2002). http://dx. doi.org/10.1021/bm015533u

[31] H. Yoshimoto, Y. M. Shin, H. Terai and J. P. Vacanti, "A biodegradable nanofiber scaffold by electrospinning and its potential for bone tissue engineering", Biomaterials 24(12), 2077-2082 (2003). http://dx. doi.org/10.1016/S0142-9612(02)00635-X

[32] J. H. Kim, P. H. Choung, I. Y. Kim, K. T. Lim, H. M. Son and Y. H. Choung, "Electrospun nanofibers composed of poly(-caprolactone) and polyethylenimine for tissue engineering applications", Mater. Sci. Eng. 
C 29(5), 1725-1731 (2009). http://dx.doi.org/10. 1016/j.msec. 2009.01.023

[33] R. Jayakumar, M. Prabaharan, S. V. Nair and H. Tamura, "Novel chitin and chitosan nanofibers in biomedical applications", Biotechnology Adv. 28(1), 142-150 (2010). http://dx.doi.org/10.1016/ j.biotechadv. 2009.11.001

[34] C. Y. Xu, R. Inai, M. Kotaki and S. Ramakrishna, "Aligned biodegradable nanofibrous structure: a potential scaffold for blood vessel engineering", Biomaterials 25(5), 877-886 (2004). http://dx.doi.org/ 10.1016/S0142-9612(03)00593-3

[35] Y. Zhang, J. R. Venugopal, A. E. Turki and S. Ramakrishna, "Electrospun biomimetic nanocomposite nanofibers of hydroxyapatite/chitosan for bone tissue engineering", Biomaterials 29(32), 4314-4322 (2008). http://dx.doi.org/10.1016/j. biomaterials. 2008.07.038

[36] Z. X. Meng, Y. S. Wang, C. Ma, W. Zheng, L. Li and Y. F. Zheng, "Electrospinning of PLGA/gelatin randomly-oriented and aligned nanofibers as potential scaffold in tissue engineering", Mater. Sci. Eng. C 30(8), 1204-1210 (2010). http://dx.doi.org/10. 1016/j.msec.2010.06.018

[37] B. M. Min, G. Lee, S. H. Kim, Y. S. Nam, T. S. Lee and W. H. Park, "Electrospinning of silk fibroin nanofibers and its effect on the adhesion and spreading of normal human keratinocytes and fibroblasts in vitro", Biomaterials 25(7-8), 1289-1297 (2004). http://dx.doi.org/10.1016/j. biomaterials. 2003.08.045

[38] S. Shao, S. Zhou, L. Li, J. Li, C. Luo, J. Wang, X. $\mathrm{Li}$ and J. Wang, "Osteoblast function on electrically conductive electrospun PLA/MWCNTs nanofibers", Biomaterials 32(11), 2821-2833 (2011). http://dx. doi.org/10.1016/j.biomaterials.2011.01.051

[39] L. Li, H. Li, Y. Qian, X. Li, G. K. Singh, L. Zhong, W. Liu, Y. Lv, K. Cai and L. Yang, "Electrospun poly(e-caprolactone)/silk fibroin core-sheath nanofibers and their potential application in tissue engineering and drug release", Int. J. Biological Macromol. 49, 223-232 (2011). http://dx.doi.org/ 10.1016/j.ijbiomac.2011.04.018

[40] N. P. Gule, M. Kwaadsteniet, T. E. Cloete and B. Klumperman, "Furanone-containing poly(vinyl alcohol) nanofibers for cell-adhesion inhibition", Water Res. 47(3), 1049-1059 (2013). http://dx.doi.org/ 10.1016/j. watres.2012.11.012

[41] D. Liang, B. S. Hsiao and B. Chu, "Functional electrospun nanofibrous scaffolds for biomedical applications", Adv. Drug Delivery Rev. 59(14), 1392-1412 (2007). http://dx.doi.org/10.1016/j.addr. 2007 . 04.021

[42] H. S. Yoo, T. G. Kim and T. G. Park, "Surfacefunctionalized electrospun nanofibers for tissue engineering and drug delivery", Adv. Drug Delivery Rev. 61(12), 1033-1042 (2009). http://dx.doi.org/ 10.1016/j.addr.2009.07.007

[43] T. J. Sill and H. A. V. Recum, "Electrospinning: Application in drug delivery and tissue engineering",
Biomaterials 29(13), 1989-2006 (2008). http://dx. doi.org/10.1016/j.biomaterials. 2008.01.011

[44] D. Yang, Y. Li and J. Nie, "Preparation of gelatin/PVA nanofibers and their potential application in controlled release of drugs", Carbohyd. Polym. 69(3), 538-543 (2007). http://dx.doi.org/10.1016/ j.carbpol. 2007.01.008

[45] C. Santoro, A. Stadlhofer, V. Hacker, G. Squadrito, U. Schroder and B. Li, "Activated carbon nanofibers (ACNF) as cathode for single chamber microbial fuel cells (SCMFCs)", J. Power Sources 243(1), 499-507 (2013). http://dx.doi.org/10. 1016/j · jpowsour. 2013.06.061

[46] C. Wu, X. Li, W. Li, B. Li, Y. Wang, Y. Wang, M. $\mathrm{Xu}$ and L. Xing, " $\mathrm{Fe}_{2} \mathrm{O}_{3}$ nanorods/carbon nanofibers composite: Preparation and performance as anode of high rate lithium ion battery", J. Power Sources 251, 85-91 (2014). http://dx.doi.org/10.1016/j. jpowsour. 2013.11.030

[47] C. Cao, L. Tan, W. Liu, J. Ma and L. Li, "Polydopamine coated electrospun poly(vinyldiene fluoride) nanofibrous membrane as separator for lithium-ion batteries", J. Power Sources 248(15), 224-229 (2014). http://dx.doi.org/10.1016/j. jpowsour. 2013.09.027

[48] H. Gwon, J. Hong, H. Kim, D. H. Seo, S. Jeon and K. Kang, "Recent progress on flexible lithium rechargeable batteries", Energy Environ. Sci. 7(2), 538-551 (2014). http://dx.doi.org/10.1039/c3ee42927j

[49] L. Yang and W. W. F. Leung, "Application of a bilayer $\mathrm{TiO}_{2}$ nanofiber photoabode for opticization of dye-sensitized solar cells", Adv. Mater. 23(39), 4559-4562 (2011). http://dx.doi.org/10. 1002/adma. 201102717

[50] L. Yang and W. W. F. Leung, "Electrospun $\mathrm{TiO}_{2}$ nanorods with carbon nanotubes for efficient electron collection in dye-sensitized solar cells", Adv. Mater. 25(12), 1792-1795 (2013). http://dx.doi.org/10. 1002/adma. 201204256

[51] X. Wang, K. Gao, Z. Shao, X. Peng, X. Wu and F. Wang, "Layer-by-Layer assembled hybrid multilayer thin film electrodes based on transparent cellulose nanofibers paper for flexible supercapacitors applications", J. Power Sources 249(1), 148-155 (2014). http://dx.doi.org/10. 1016/j . jpowsour . 2013.09.130

[52] V. Thavasi, G. Singh and S. Ramakrishna, "Electrospun nanofibers in energy and environmental applications", Energy Environ. Sci. 1, 205-221 (2008). http://dx.doi.org/10.1039/B809074M

[53] M. C. Beilke, J. W. Zewe, J. E. Clark and S. V. Olesik, "Aligned electrospun nanofibers for ultrathin layer chromatography", Analytica Chimica Acta 761(25), 201-208 (2013). http://dx.doi.org/10. 1016/j.aca.2012.11.028

[54] N. A. M. Barakat, A. A. Elzatahry and K. A. Khalil, "Synthesis and characterization of Co-Mn-O nanofibers supported on a graphite disk: Novel strategy for nanofibers immobilization", Mater. Res. Bull. 
49, 503-508 (2014). http://dx.doi.org/10.1016/j. materresbull.2013.09.026

[55] J. Liu, J. Shi, L. Jiang, F. Zhang, L. Wang, S. Yamamoto, M. Takano, M. Chang, H. Zhang and Y. Chen, "Segmented magnetic nanofibers for single cell manipulation", Appl. Surf. Sci. 258(19), 7530-7535 (2012). http://dx.doi.org/10.1016/j. apsusc. 2012.04.077

[56] M. S. Hassan, T. Amna, F. A. Sheikh, S. S. Al-Deyab, K. E. Choi, I. H. Hwang and M. S. Khil, "Bimetallic $\mathrm{Zn} / \mathrm{Ag}$ doped polyurethane spider net composite nanofibers: A novel multipurpose electrospun mat", Ceramics Int. 39(3), 2503-2510 (2013). http://dx. doi.org/10.1016/j.ceramint. 2012.09.009

[57] Abdal-hay, L. D. Tijing and J. K. Lim, "Characterization of the surface biocompatibility of an electrospun nylon 6/CaP nanofiber scaffold using osteoblasts", Chem. Eng. J. 215-216(15), 57-64 (2013). http:// dx.doi.org/10.1016/j.cej.2012.10.046

[58] R. Nirmala, K. T. Nam, R. Navamathavan, S. J. Park and H. Y. Kim, "Hydroxyapatite mineralization on the calcium chloride blended polyurethane nanofiber via biomimetic method", Nanoscale Res. Lett.6, 2-10 (2011). http://dx.doi.org/10.1007/ s11671-010-9737-4

[59] R. Nirmala, R. Navamathavan, M. H. E. Newehy and H. Y. Kim, "Preparation and characterization of electrospun ultrafine polyamide-6 nanofibers", Polym. Int. 60(10), 1475-1480 (2011). http://dx.doi.org/ 10.1002/pi. 3105

[60] X. Wang, B. Ding, J. Yu and J. Yang, "Large-scale fabrication of two-dimensional spider-web-like gelatin nanonets via electro-netting", Colloid. Surf. B: Biointerfaces 86(2), 345-352 (2011). http://dx.doi.org/ 10.1016/j.colsurfb.2011.04.018

[61] X. Ca, X. Wang, B. Ding, J. Yu and G. Sun, "Novel spider-web-like nanoporous networks based on jute cellulose nanowhiskers", Carbohydrate Polymers 92(2), 2041-2047 (2013). http://dx.doi.org/ 10.1016/j.carbpol.2012.11.085

[62] H. R. Pant, B. Pant, P. Pokharel, H. J. Kim, L. D. Tijing, C. H. Park, D. S. Lee, H. Y. Kim and C. S. Kim, "Photocatalytic $\mathrm{TiO}_{2}-\mathrm{RGO} /$ nylon6 spider-wave-like nano-nets via electrospinning and hydrothermal treatment", J. Membr. Sci. 429, 225234 (2013). http://dx.doi.org/10.1016/j.memsci. 2012.11.025

[63] Abdal-hay, H. R. Pant and J. K. Lim, "Superhydrophilic electronspun nylon-6/hydroxyapatite membrane for bone tissue engineering", European Polym. J. 49(6), 1314-1321 (2013). http://dx.doi. org/10.1016/j. eurpolymj . 2013.02.004

[64] R. Nirmala, H. R. Panth, C. Yi, K. T. Nam, S. J. Park and H. Y. Kim, "Effect of solvents on high aspect ratio polyamide- 6 nanofibers via electrospinning", Macromol. Res. 18(8), 75-84 (2010). http:// dx.doi.org/10.1007/s13233-010-0808-2

[65] R. Nirmala, K. T. Nam, S. J. Park, Y. S. Shin, R. Navamathavan and H. Y. Kim, "Formation of high aspect ratio polyamide- 6 nanofibers via electrically induced double layer during electrospinning", Appl. Surf. Sci. 256(21), 6318-6323 (2010). http://dx.doi . org/10.1016/j. apsusc. 2010.04.010

[66] H. R. Pant, M. P. Bajgai, K. T. Nam, K. H. Chu, S. J. Park and H. Y. Kim, "Formation of electrospun nylon-6/methoxy poly(ethylene glycol) oligomer spider-wave nanofibers", Mater. Lett. 64(19), 2087-2090 (2010). http://dx.doi.org/10. 1016/j.matlet.2010.06.047

[67] H. R. Pant, M. P. Bajgai, C. Yi, R. Nirmala, K. T. Nam, W. Baek and H. Y. Kim, "Effect of successive electrospinning and the strength of hydrogen bond on the morphology of electrospun nylon- 6 nanofibers", Colloid. Surf. A Physicochemical Eng. Aspects 370(1-3), 87-94 (2010). http://dx.doi.org/ 10.1016/j.colsurfa. 2010.08.051

[68] B. Ding, T. Ogawa, J. Kim, K. Fujimoto and S. Shiratori, "Fabrication of a super-dydrophobi nanofibrous zinc oxide film surface by electrospinning", Thin Solid Films 516(9), 2495-2501 (2008). http://dx.doi.org/ $10.1016 / j$.tsf. 2007.04 .086

[69] Z. Dong, S. J. Kennedy and Y. Wu, "Electrospinning materials for energy-related applications and devices", J. Power Sources 196(11), 4886-4904 (2011). http://dx.doi.org/10.1016/j. jpowsour.2011.01.090

[70] R. Nirmala, R. Navamathavan, M. H. E. Newehy and H. Y. Kim, "Preparation and electrical characterization of polyamide-6/chitosan composite nanofibers via electrospinning", Mater. Lett. 65(3), 493496 (2011). http://dx.doi.org/10.1016/j.matlet. 2010.10 .066

[71] B. Ding, C. Li, Y. Miyauchi, O. Kuwaki and S. Shiratore, "Formation of novel 2D polymer nanowebs via electrospinning", Nanotechnology 17(15), 3685-3691 (2006). http://dx.doi.org/10. 1088/0957-4484/17/15/011

[72] D. C. Parajuli, M. P. Bajgai, J. A. Ko, H. K. Kang, M. S. Khil and Kim, "Synchronized polymerization and fabrication of poly(acrylic acid) and nylon hybrid mats in electrospinning", ACS Appl. Mater. Interfaces 1(4), 750-757 (2009). http://dx.doi.org/10. $1021 / a m 800191 \mathrm{~m}$

[73] S. Das, A. S. Wajid, S. K. Bhattacharia, M. D. Wilting, I. V. Rivero and M. J. Green, "Electrospinning of polymer nanofibers loaded with noncovalently functionalized graphene", J. Appl. Polym. Sci. 128(6), 4040-4046 (2013). http://dx.doi.org/ 10.1002/app. 38694

[74] Y. Yang, Z. Guo, H. Zhang, D. Huang, J. Gu, Z. Huang, F. Kang, T. A. Hatton and G. C. Rutledge, "Electrospun magnetic carbon composite fibers: Synthesis and electromagnetic wave absorption characteristics", J. Appl. Polym. Sci. 127(6), 4288-4295 (2013). http://dx.doi.org/10.1002/app. 38027

[75] L. V. Karabanova R. L. D. Whitby, A. Korobeinyk, O. Bondaruk, J. P. Salvage, A. W. Lloyd and S. V. Mikhalovsky, "Microstructure changes of polyurethane by inclusion of chemically modified carbon nanotubes at low filler contents", Comp. Sci. 
Technol. 72(8), 865-872 (2012). http://dx.doi.org/ 10.1016/j. compscitech. 2012.02.008

[76] J. Lin, B. Ding, J. Yu and Y. Hsieh, "Direct fabrication of highly nanoporous polystyrene Fibers via Electrospinning", ACS Appl. Mater. Interf. 2(2), 521528 (2010). http://dx.doi.org/10.1021/am900736h

[77] N. Bhardwaj and S. C. Kundu, "Electrospinning: A fascinating fiber fabrication technique", Biotechnol. Adv. 28(3), 325-347 (2010). http://dx.doi.org/10. 1016/j.biotechadv . 2010.01.004

[78] A. Lancuski, S. Fort and F. Bossard, "Electrospun azido-PCL nanofibers for enhanced surface functionalization by click chemistry", ACS Appl. Mater. Interf. 4(12), 6499-6504 (2012). http://dx.doi.org/ 10.1021/am301458y

[79] M. Huang, Y. Si, X. Tang, Z. Zhu, B. Ding, L. Liu, G. Zheng, W. Luo and J. Yu, "Gravity driven separation of emulsified oil-water mixtures utilizing in situ polymerized superhydrophobic and superoleophilic nanofibrous membranes", J. Mater. Chem. A 1(45), 14071-14074 (2013). http://dx.doi.org/ 10.1039/C3TA13385K

[80] J. Miao, M. Miyauchi, T. J. Simmons, J. S. Dordick and R. J. Linhardt, "Electrospinning of nanomaterials and applications in electronic components and devices", J. Nanosci. Nanotechnol. 10(9), 5507-5519 (2010). http://dx.doi.org/10. 1166/jnn. 2010.3073

[81] W. Teo and S. Ramakrishna, "A review on electrospinning design and nanofiber assemblies", Nanotechnology 17(14), R89-R106 (2006). http://dx. doi.org/10.1088/0957-4484/17/14/R01

[82] X. Wang, B. Ding, G. Sun, M. Wang and J. Yu, "Electro-spinning/netting: A strategy for the fabrication of three-dimensional polymer nano-fiber/nets" Prog. Mater. Sci. 58(8), 1173-1243 (2013). http:// dx.doi.org/10.1016/j.pmatsci.2013.05.001

[83] L. Persano, C. Dagdeviren, Y. Su, Y. Zhang, S. Girardo, D. Pisignano, Y. Huang and J. A. Rogers, "High performance piezoelectric devices based on aligned arrays of nanofibers of poly(vinylidenefluoride-co-trifluoroethylene)", Nat. Commun. 4, 1633(2013). http://dx.doi.org/10. $1038 /$ ncomms 2639

[84] H. Cho, S. Y. Min and T. W. Lee, "Electrospun organic nano?ber electronics and photonics", Macromol. Mater. Eng. 298(5), 475-486 (2013). http://dx. doi .org/10.1002/mame. 201200364

[85] D. Li and Y. Xia, "Electrospinning on nanofibers: Reinventing the wheel?", Adv. Mater. 16(14), 1151-1170 (2004). http://dx.doi.org/10.1002/ adma. 200400719

[86] Z. M. Huang, Y. Z. Zhang, M. Kotaki and S. Ramakrishna, "A review on polymer nanofibers by electrospinning and their applications in nanocomposites", Comp. Sci. Technol. 63(15), 2223-2253 (2003). http://dx.doi.org/10.1016/ S0266-3538(03) 00178-7

[87] D. H. Reneker and A. L. Yarin, "Electrospinning jets and polymer nanofibers", Polymer 49(10),
2387-2425 (2008). http://dx.doi.org/10.1016/j. polymer.2008.02.002

[88] S. Ramakrishna, K. Fujihara, W. E. Teo1, T. Yong, Z. Ma and R. Ramaseshan, "Electrospun nanofibers: solving global issues", Mater. Today $9(3), \quad 40-50$ (2006). http://dx.doi.org/10.1016/ S1369-7021 (06) 71389-X

[89] X. Wang, B. Ding, J. Yu and M. Wang, "Engineering biomimetic superhydrophobic surfaces of electrospun nanomaterials", Nano Today 6(5), 510530 (2011). http://dx.doi.org/10.1016/j.nantod. 2011.08 .004

[90] L. Persano, A. Camposeo, C. Tekmen and D. Pisignano, "Industrial upscaling of electrospinning and applications of polymer nanofibers: A review", Macromol. Mater. Eng. 298(5), 504-520 (2013). http://dx. doi.org/10.1002/mame. 201200290

[91] C. J. Luo, S. D. Stoyanov, E. Stride, E. Pelan and M. Edirisinghe, "Electrospinning versus ?bre production methods: from specifics to technological convergence", Chem. Soc. Rev. 41(13), 4708-4735 (2012). http://dx.doi.org/10.1039/C2CS35083A

[92] G. I. Taylor, "Disintegration of water drops in an electric field", Proc. R. Soc. London Ser. A 280(1382), 383-397 (1964). http://dx.doi.org/10.1098/rspa. 1964.0151

[93] G. I. Taylor, "The circulation produced in a drop by an electric field", Proc. R. Soc. London Ser. A 291(1425), 159-166 (1966). http://dx.doi.org/10. 1098/rspa. 1966.0086

[94] G. I. Taylor, "Electrically driven jets", Proc. R. Soc. London Ser. A 313(1515), 453-475 (1969). http:// dx.doi.org/10.1098/rspa.1969.0205

[95] H. R. Allcock, F. W. Lampe, and J. E. Mark, "Contemporary Polymer Chemistry", $3^{\text {rd }}$ Edition, Pearson Education, Inc. New Jersey, 2003, p.647.

[96] P. Supaphol, C. M. Uppatham and M. Nithitanakul, "Ultrafine electrospun polyamide- 6 fibers: Effects of solvent system and emitting electrode polarity on morphology and average fiber diameter", Macromol. Mater. Eng. 290(9), 933-942 (2005). http://dx.doi. org/10.1002/mame. 200500024

[97] A. Patlolla, G. Collins and T. L. Arinzeh, "Solventdependent properties of electrospun fibrous composites for bone tissue regeneration", Acta Biomaterialia 6(1), 90-101 (2010). http://dx.doi.org/10.1016/j. actbio. 2009.07.028

[98] P. K. Baumgarten, "Electrostatic spinning of acrylic microfibers", J. Colloid. Interface Sci. 36(1), 71-79 (1971). http://dx.doi.org/10.1016/ 0021-9797 (71) 90241-4

[99] M. Montaudo and C. Puglisi, "Essential role of chain ends in the Ny6/PBT exchange: A combined NMR and MALDI approach", Macromolecules 36(19), 7143-7154 (2003). http://dx.doi.org/10. 1021/ma0346153

[100] J. R. Schaefgen and C. F. Trivisonno, "Polyelectrolyte behavior of polyamides. I. viscosities of solutions of linear polyamides in formic acid and in 
aulfuric acid", J. Am. Chem. Soc. 73(10), 4580-4585 (1951). http://dx.doi.org/10.1021/ja01154a024

[101] J. E. McGrath, "Ring-Opening Polymerization", American Chemical Society, Washington D.C. p7 (1985).

[102] H. Zhao and H. H. Bau, "On the effect of induced electro-osmosis on a cylindrical particle next to a surface", Langmuir 23(7), 4053-4063 (2007). http://dx. doi.org/10.1021/la063224p

[103] W. Sigmund, J. Yuh, H. Park, V. Maneeratana, G. Pyrgiotakis and A. Daga, "Processing and structure relationship of ceramic fiber systems", J. Am. Ceram. Soc. 89(2), 395-407 (2006). http://dx.doi.org/10. 1111/j.1551-2916.2005.00807.x

[104] S. D. Vrieze, P. Westbroek, T. V. Camp and K. D. Clerck, "Solvent system for steady state electrospinning of polyamide 6.6", J. Appl. Polym. Sci. 115(2), 837-842 (2010). http://dx.doi.org/10.1002/app. 30331

[105] K. Behler, M. Havel and Y. Gogotsi, "New solvent for polyamides and its application to the electrospinning of polyamides 11 and 12", Polymer 48(22), 6617-6621 (2007). http://dx.doi.org/10.1016/j. polymer.2007.08.058

[106] C. Mit-uppatham, M. Nithitanakul and P. Supaphol, "Ultrafine electrospun polyamide-6 fibers: effect of solution conditions on morphology and average fiber diameter", Macromol. Chem. Phys. 205(17), 2327-2338 (2004). http://dx.doi.org/10. 1002/macp. 200400225

[107] R. L. Grimm and J. L. Beauchamp, "Dynamics of field-induced droplet ionization: time-resolved studies of distortion, jetting, and progeny formation from charged and neutral methanol droplets exposed to strong electric fields", J. Phys. Chem. B 109(16), 8244-8250 (2005). http://dx.doi.org/10. 1021/jp0450540

[108] F. Eustache, P. I. Dalko and J. Cossy, "Enantioselective monoreduction of 2-alkyl-1,3-diketones mediated by chiral ruthenium catalysts dynamic kinetic resolution", Org. Lett. 4(8), 1263-1265 (2002). http://dx. doi.org/10.1021/o1025527q

[109] N. Uematsu, A. Fujii, S. Hashiguchi, T. Ikariya and R. Noyori, "Asymmetric transfer hydrogenation of imines", J. Am. Chem. Soc. 118(20), 4916-4917 (1996). http://dx.doi.org/10.1021/ja960364k

[110] D. S. Matharu and D. J. Morris, "A stereochemically well-defined rhodium(III) catalyst for asymmetric transfer hydrogenation of ketones", Org. Lett. $7(24)$, 5489-5491 (2005). http://dx.doi.org/10. 1021/o1052559f
[111] S. J. Park, D. C. Parajuli, M. P. Bajgai, K. U. Jeong, N. A. M. Barakat and H. Y. Kim, "MultiWalled Carbon Nanotubes Fabricated by Electrospinning of Acrylonitrile/Nylon Solution and Subsequent Carbonization", J. Nanosci. Nanotechnol. 10(8), 1-4 (2010). http://dx.doi.org/10.1166/jnn. 2010.2417

[112] H. R. Pant, D. R. Pandeya, K. T. Nam, W. Baek, S. T. Hong and H. Y. Kim, "Photocatalytic and antibacterial properties of $\mathrm{TiO}_{2} /$ nylon-6 electrospun nanocomposites mat containing silver nanoparticles", J. Haz. Mater. 189(1-2), 465-471 (2011). http://dx. doi.org/10.1016/j.jhazmat.2011.02.062

[113] H. R. Pant, M. P. Bajgai, K. T. Nam, Y. A. Seo, D. R. Pandeya and S. T. Hong, "Electrospun nylon-6 spider-net like nanofiber mat containing $\mathrm{TiO}_{2}$ nanoparticles: A multifunctional nanocomposite textile material", J. Haz. Mater.185(1), 124-130 (2011). http://dx.doi.org/ 10.1016/j.jhazmat. 2010.09.006

[114] R. Nirmala, J. W. Jeong, R. Navamathavan and H. Y. Kim, "Synthesis and electrical properties of $\mathrm{TiO}_{2}$ nanoparticles embedded in polyamide- 6 nanofibers via electrospinning", Nano-Micro Lett. 3(1), 5661 (2011). http://dx.doi.org/10.3786/nml.v3i1. p56-61

[115] R. Nirmala, J. W. Jeong, H. J. Oh, R. Navamathavan, M. E. Newehy, S. S. Al-Deyab and H. Y. Kim, "Electrical properties of ultrafine nylon-6 nanofibers prepared via electrospinning", Fibers and Polymers 12(8), 1021-1024 (2011). http://dx.doi. org/10.1007/s12221-011-1021-4

[116] X. Wang, B. Ding, J. Yu and M. Wang, "Highly sensitive humidity sensors based on electrospinning/netting a polyamide 6 nano-fiber/net modified by polyethyleneimine", J. Mater. Chem. 21, 16231-16238 (2011). http://dx.doi.org/10.1039/ C1JM13037D

[117] R. Nirmala, H. M. Park, R. Navamathavan, H. S. Kang, M. H. E. Newehy and H. Y. Kim, "Lecithin blended polyamide- 6 high aspect ration nanofiber scaffolds via electrospinning for human osteoblast cell culture", Mater. Sci. Eng. C 31(2), 486-493 (2011). http://dx.doi.org/10.1016/j.msec.2010.11.013

[118] R. Nirmala, R. Navamathavan, H. S. Kang, M. H. E. Newehy and H. Y. Kim, "Preparation of polyamide- $6 /$ chitosan composite nanofibers by a single solvent system via electrospinning for biomedical applications", Colloid. Surf. B Biointerfaces 83(1), 173-178 (2011). http://dx.doi.org/10.1016/ j.colsurfb.2010.11.026 